\title{
Distinguishing between stress-induced and structural anisotropy at Mount Ruapehu volcano, New Zealand
}

\author{
Jessica H. Johnson, ${ }^{1,2}$ Martha K. Savage, ${ }^{1}$ and John Townend ${ }^{1}$ \\ Received 17 February 2011; revised 1 August 2011; accepted 20 September 2011; published 14 December 2011.
}

[1] We have created a benchmark of spatial variations in shear wave anisotropy around Mount Ruapehu, New Zealand, against which to measure future temporal changes.

Anisotropy in the crust is often assumed to be caused by stress-aligned microcracks, and the polarization of the fast quasi-shear wave $(\phi)$ is thus interpreted to indicate the direction of maximum horizontal stress, but can also be due to aligned minerals or macroscopic fractures. Changes in seismic anisotropy have been observed following a major eruption in 1995/96 and were attributed to changes in stress from the depressurization of the magmatic system. Three-component broadband seismometers have been deployed to complement the permanent stations that surround Ruapehu, creating a combined network of 34 threecomponent seismometers. This denser observational network improves the resolution with which spatial variations in seismic anisotropy can be examined. Using an automated shear wave splitting analysis, we examine local earthquakes in 2008. We observe a strong azimuthal dependence of $\phi$ and so introduce a spatial averaging technique and twodimensional tomography of recorded delay times. The anisotropy can be divided into regions in which $\phi$ agrees with stress estimations from focal mechanism inversions, suggesting stress-induced anisotropy, and those in which $\phi$ is aligned with structural features such as faults, suggesting structural anisotropy. The pattern of anisotropy that is inferred to be stress related cannot be modeled adequately using Coulomb modeling with a dike-like inflation source. We suggest that the stress-induced anisotropy is affected by loading of the volcano and a lithospheric discontinuity.

Citation: Johnson, J. H., M. K. Savage, and J. Townend (2011), Distinguishing between stress-induced and structural anisotropy at Mount Ruapehu volcano, New Zealand, J. Geophys. Res., 116, B12303, doi:10.1029/2011JB008308.

\section{Introduction}

\subsection{Overview}

[2] In this paper we present shear wave splitting results from a combined network of 34 broadband and short-period three-component seismometers. This combined network is denser than those used in previous studies and so yields results with higher resolution of spatial variations in anisotropy. We use both shallow $(<30 \mathrm{~km})$ and deep $(>50 \mathrm{~km})$ earthquakes that occurred throughout 2008 near Mt. Ruapehu and the automated shear wave splitting method of Savage et al. [2010a] to measure anisotropy parameters. We employ a spatial averaging technique similar to that of Audoine et al. [2004] combined with a new method of two-dimensional tomography to analyze spatial variations in anisotropy and

\footnotetext{
${ }^{1}$ School of Geography, Environment and Earth Sciences, Victoria University of Wellington, Wellington, New Zealand.

${ }^{2}$ Now at Hawaiian Volcano Observatory, USGS, Hawaii National Park, Hawaii, USA.

Copyright 2011 by the American Geophysical Union. 0148-0227/11/2011JB008308
}

relate these to stress and structure in the region. The Coulomb stress package of Lin and Stein [2004] and Toda et al. [2005] is used to predict stress orientations consistent with a putative magma reservoir model and determine whether they are consistent with the anisotropy in regions where stress dominates. The results of this study will be used to detect future changes in anisotropy and to identify regions of past changes in anisotropy with more confidence.

[3] Mount Ruapehu is a $2797 \mathrm{~m}$-high andesitic stratovolcano and the largest active volcano in New Zealand (Figure 1). It is the southernmost of the large active volcanoes on the North Island, which make up the Taupo Volcanic Zone (TVZ). The TVZ is a spreading segment of the Earth's crust resulting from the subduction of the Pacific Plate beneath the Australian Plate at the obliquely westward dipping Hikurangi subduction zone. Subsidence in the central axis of the TVZ at the southern termination has led to prominent active faults developing to the east and west of Mt. Ruapehu, which are down-thrown toward the mountain [Villamor and Berryman, 2006]. The ring plain is composed of laharic, fluvial, pyroclastic and fall deposits [Houghton et al., 1987], indicating that Mt. Ruapehu produces different styles of eruptions, some of which have the potential to be devastating to the surrounding area [Neall et al., 1999]. The principal road and rail routes of the central North 


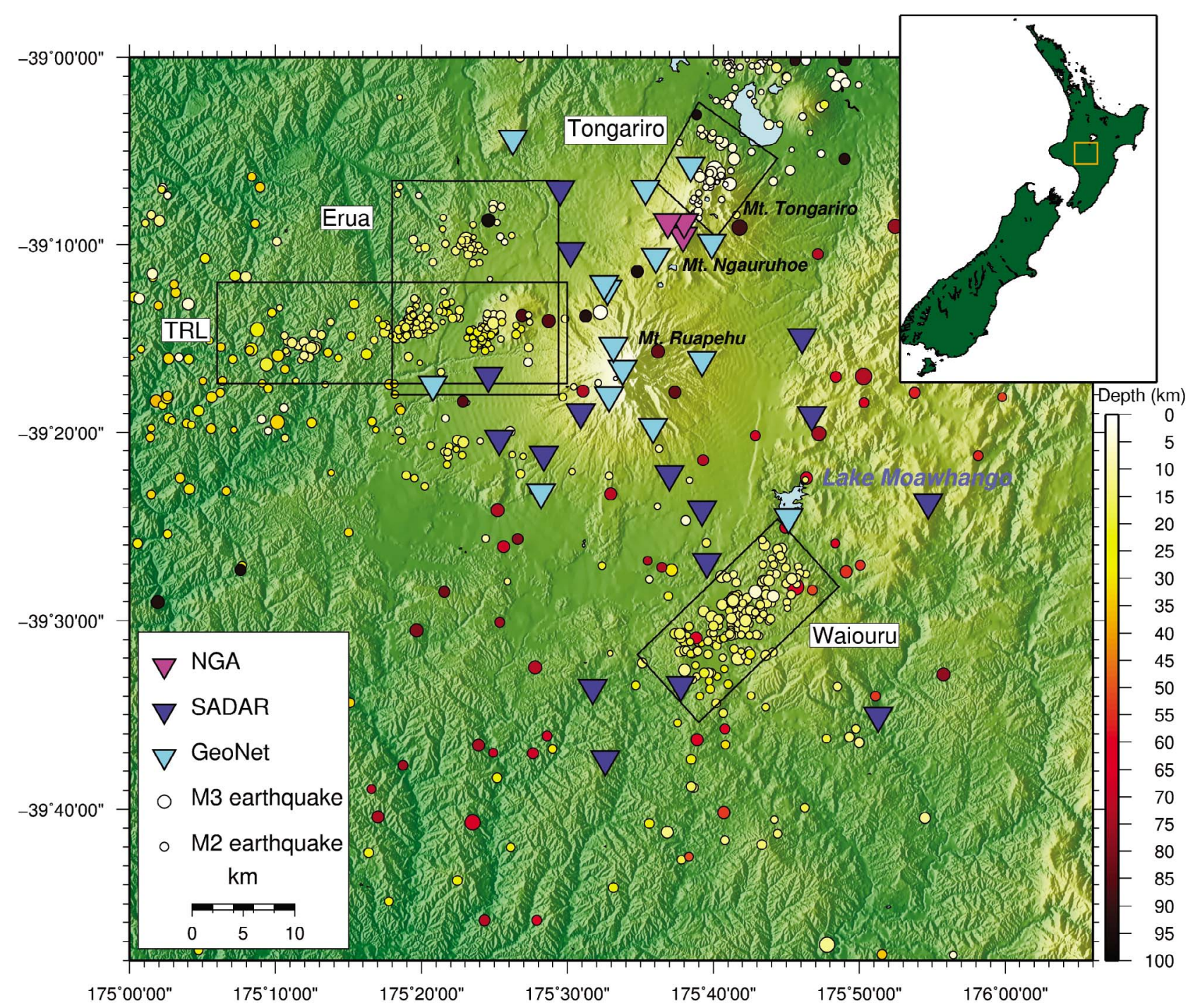

Figure 1. Map of the area around Mount Ruapehu (central peak). The circles indicate the catalog locations of the earthquakes in 2008, used in this study, scaled by magnitude and color-coded by depth. The inverted triangles represent three-component seismometers; the cyan are permanent GeoNet stations, the blue are temporary SADAR stations and the purple are temporary Ngauruhoe stations. Boxes represent clusters of earthquakes; see text for a discussion.

Island cross the ring plain east and west of the volcano and there are three ski fields on the mountain, all of which are in high risk zones [Houghton et al., 1987]. Major magmatic eruptions occurred in 1945 and 1995/1996; the latter was the largest historical eruption of Mt. Ruapehu, producing a $12 \mathrm{~km}$ high volcanic ash plume and lahars on the flanks of the volcano [Bryan and Sherburn, 1999]. Mt. Ruapehu frequently experiences phreatic and phreato-magmatic eruptions [Hurst et al., 2004], which also threaten lives and property [Johnston et al., 2000].

[4] Eruptions of Mt. Ruapehu often occur with few or no detectable precursors, making prediction difficult [Hurst et al., 2004]. For this reason Mt. Ruapehu volcano has, in recent years, been subject to several studies of crustal seismic anisotropy using shear wave splitting analysis [Miller and
Savage, 2001; Gerst and Savage, 2004] in an attempt to characterize the local stress regime.

\subsection{Previous Studies of Seismic Anisotropy}

[5] Miller and Savage [2001] measured shear wave splitting from shallow $(<30 \mathrm{~km})$ and deep $(>50 \mathrm{~km})$ earthquakes in 1994 and 1998 and observed a change in the dominant azimuth of fast polarization $(\phi)$ spanning the magmatic eruption of 1995/1996. That study was extended by Gerst and Savage [2004], who used the same techniques and an additional deployment of three-component seismometers in 2002 to observe further changes in $\phi$.

[6] The changes in $\phi$ in both studies were interpreted as being caused by a dike-shaped magma reservoir, or system of dikes, trending NE-SW. According to this model, the 
magma reservoir was pressurized before the eruption, producing a local stress field different from the regional stress field. Following the eruption the reservoir was less full and correspondingly less pressurized so the local stress returned to that of the surrounding region. The Gerst and Savage [2004] study suggested that the later changes in $\phi$ were due to repressurizing of the reservoir in response to an increase of magma in the system. The stress in the surrounding crust caused by the pressurized magma reservoir is thought to preferentially align randomly oriented fluid-filled microcracks and cause seismic anisotropy that is detected through shear wave splitting [e.g., Crampin, 1994; Hatchell and Bourne, 2005]. While aligned, these microcracks are anisotropic structures but they are transient with the changing stress and so we refer to this cause of anisotropy as stress-induced anisotropy. Crustal media with prominent structures such as layers, parallel fractures or lineated fabric can also be anisotropic [e.g., Kaneshima, 1990; Babuska and Cara, 1991; Boness and Zoback, 2006]. When the structures exhibit horizontal axes of symmetry, a vertically propagating shear wave will also be split and we refer to this intrinsic anisotropy as structural anisotropy. This complicates interpretation of shear wave splitting measurements because the possibility of both structural anisotropy and stress-induced anisotropy must be considered.

[7] Kaneshima [1990] examined fast shear wave polarization throughout Japan and attributed the observations to three mechanisms: stress-induced microcracks; cracks or fractures in the vicinity of active faults; and intrinsic rock properties from preferred orientation of minerals. Zinke and Zoback [2000] detected both stress-induced and structure related anisotropy at the same station in central California and distinguished between the two mechanisms by observing that different clusters of earthquakes gave different fast polarizations, thereby showing in that case that the shallow crust beneath the station did not influence the shear wave splitting. Boness and Zoback [2006] measured shear wave anisotropy at stations on and around the San Andreas Fault and found by interpreting $\phi$ orientations in conjunction with the fault strikes and regional maximum horizontal compressive stress from borehole breakouts, that separate regions of structural and stress-induced anisotropy could be identified.

[8] If we can differentiate between stress-induced and structural anisotropy then shear wave splitting analysis has the potential to be developed into a near-real time stressmonitoring tool. This could be a valuable addition to the monitoring arsenal at Mt. Ruapehu and other volcanoes that exhibit little precursory activity before eruptions.

\subsection{Regional Geology}

[9] The basement greywacke in the Ruapehu region consists of the Torlesse and Waipapa terranes to the west and east respectively [Adams et al., 1998; Mortimer, 2004]. The geological textures of the basement rocks around Mt. Ruapehu were investigated by Beetham and Watters [1985] during the Tongariro Power development project. They found no discernible internal structure in the basement greywacke except a couple of small areas that display textural zone $2 \mathrm{~B}$, semischistose rocks (on the metamorphic sequence described by Turnbull et al. [2001]); these were to the north of the
Kaimanawa Range (which is outside our study area) and around Lake Moawhango (Figure 1). This is therefore the only region in which we expect to observe anisotropy related to the metamorphic texture. Anisotropy from the semi-schistose rocks would have $\phi$ oriented in the same direction as the strike of the fabric, that is $035-040^{\circ}$.

[10] Figure 2a displays four zones identified by Villamor and Berryman [2006] as having different fault strikes. The area of most dense faulting lies to the NE of Mt. Ruapehu (zone 1), around Mt. Ngauruhoe and Mt. Tongariro. The average strike of zone 1 faults is $030^{\circ}$ [Rowland and Sibson, 2001]. The strike of zone 2 faults of $010^{\circ}$ corresponds to the axis of the Ruapehu graben. Faults in zone 2 cross-cut the faults of zones 3 to the west and zone 4 to the east. Zone 4 faults strike NNE-SSW and the zone incorporates the area of the more pervasive metamorphic fabric, which is subparallel to the fault strikes. Zone 3 faults strike WNW-ESE in an area of Tertiary marine deposits and Quaternary volcanics, however there is no information about deeper basement fabric for this zone.

\subsection{Stress Estimates}

[11] Villamor and Berryman [2006] noted that all of the Tertiary faults in the area are normal, suggesting that the maximum compressive stress, $S_{1}$, is close to vertical. In a normal faulting regime the minimum compressive stress $\left(S_{3}\right)$ corresponds to the minimum horizontal compressive stress $\left(S_{H \min }\right)$ and for Andersonian fault orientations, is orthogonal to the fault strike. Conversely, the maximum horizontal compressive stress $\left(S_{H \max }\right)$ is parallel to fault strike, in which case we would expect $\phi$ to also be parallel to fault strike regardless of whether stress-induced or structural anisotropy due to fault zones were dominant. The crosscutting of contemporary fault sets with three different strikes suggests that the minimum and intermediate principal values of the stress tensor are similar in magnitude, in which case small changes in horizontal stress magnitudes might rotate $S_{H \max }$ [Villamor and Berryman, 2006]. Further evidence that $\left|S_{2}\right| \approx\left|S_{3}\right|$ in the Ruapehu region comes from Wallace et al. [2004], who modeled GPS observations with block rotation that allows opening of the Taupo rift and implies a change in stress orientation over a short distance due to compression at the southern termination of the TVZ. The temporal changes in shear wave splitting in the region observed by Miller and Savage [2001] and Gerst and Savage [2004] are also in accordance with this hypothesis.

[12] Estimates of local stress parameters have been calculated by inverting first motions and focal mechanisms of local earthquakes. A summary of these stress estimates can be found in Table S1 in the auxiliary material. ${ }^{1}$ These calculated or inferred maximum horizontal compressive stresses will subsequently be referred to as $S_{H \max }^{\text {focal }}$.

[13] We carried out similar stress inversions to Sherburn et al. [2009] using the Bayesian method of Arnold and Townend [2007] but using slightly different clusters in order to better compare stress orientations to the zones of similar fault strikes previously described in section 1.3 and displayed in Figure 2. The focal mechanisms used in the

\footnotetext{
${ }^{1}$ Auxiliary materials are available in the HTML. doi:10.1029/ 2011JB008308.
} 


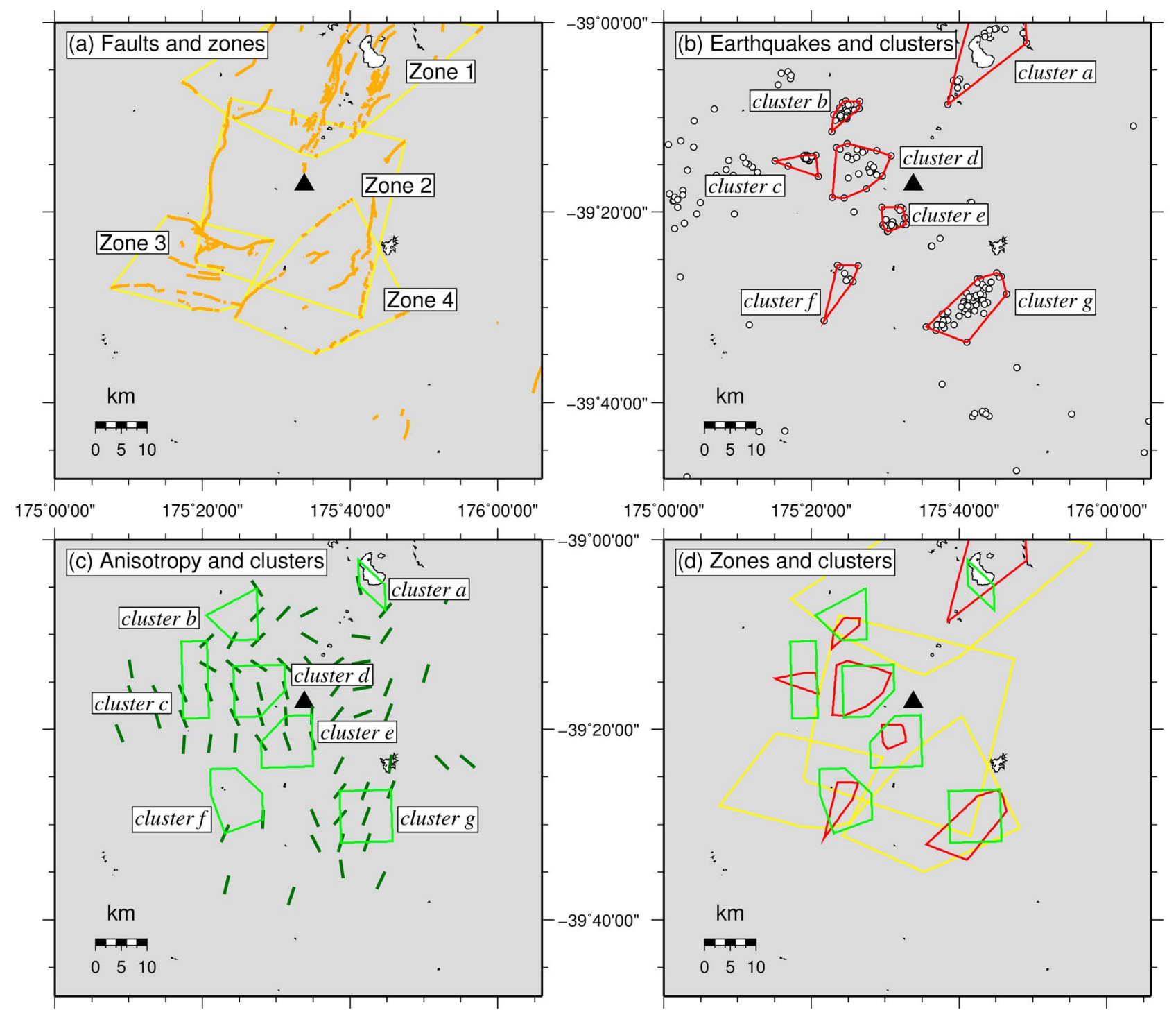

Figure 2. Zones and clusters for comparison of parameters. Black triangles indicate the summit of Mt. Ruapehu. (a) Orange lines are known faults (from the NZ Active Faults Database of GNS), yellow boxes group faults with similar strikes into four zones [Villamor and Berryman, 2006]. Zone 1 contains the Tongariro graben, zone 2 contains the Ruapehu Graben, zone 3 contains the Ohakune-Raetihi faultset and zone 4 contains the Karioi fault-set. (b) White dots show epicenters of earthquakes with focal mechanism information from Sherburn et al. [2009], red boxes group the earthquakes into seven clusters. (c) Dark green bars show fast polarization results from spatial averaging in section 4.2, green boxes show groups of data within $10 \mathrm{~km}$ of earthquake cluster centroid in Figure 2b. (d) Combination of all zone and cluster outlines.

inversions are those calculated using first motions and the FPFIT method [Reasenberg and Oppenheimer, 1985] by Sherburn et al. [2009] for well-recorded earthquakes using parameters from the GeoNet earthquake database. Figure 3a displays the epicenters of those earthquakes with calculated focal mechanisms, and the focal mechanisms are displayed in Figure $3 \mathrm{~b}$. The focal mechanism inversion method allows fault pane ambiguities, observational errors, and weights associated with individual focal mechanisms to be incorporated into the analysis. The clustering and resulting principal stresses can be seen in Figure 3. For cluster $a$ we used earthquakes that were all within our study area and fault zone 1 (Figure 2), which resulted in a smaller subset than that used by Sherburn et al. [2009], but we get stress tensor results that are in good agreement, with $S_{H \max }^{\text {focal }}$ of $103 \pm 15^{\circ}$. We created four clusters of earthquakes from zone 2, all of which were to the west of Mt. Ruapehu. The three from within the Erua cluster $(b, c$ and $d)$ give the same $S_{H \max }^{\text {focal }}$ orientation of $108 \pm 19^{\circ}$ but the one closer to the mountain (d) gave a normal faulting regime $\left(S_{1}\right.$ vertical) whereas the other two gave strike-slip ( $S_{2}$ vertical). The northernmost of these three clusters $(b)$ is in the overlap between zones 1 and 2 (Figure 2). The cluster that Sherburn et al. [2009] used to the south-west of Mt. Ruapehu was split into two, the 


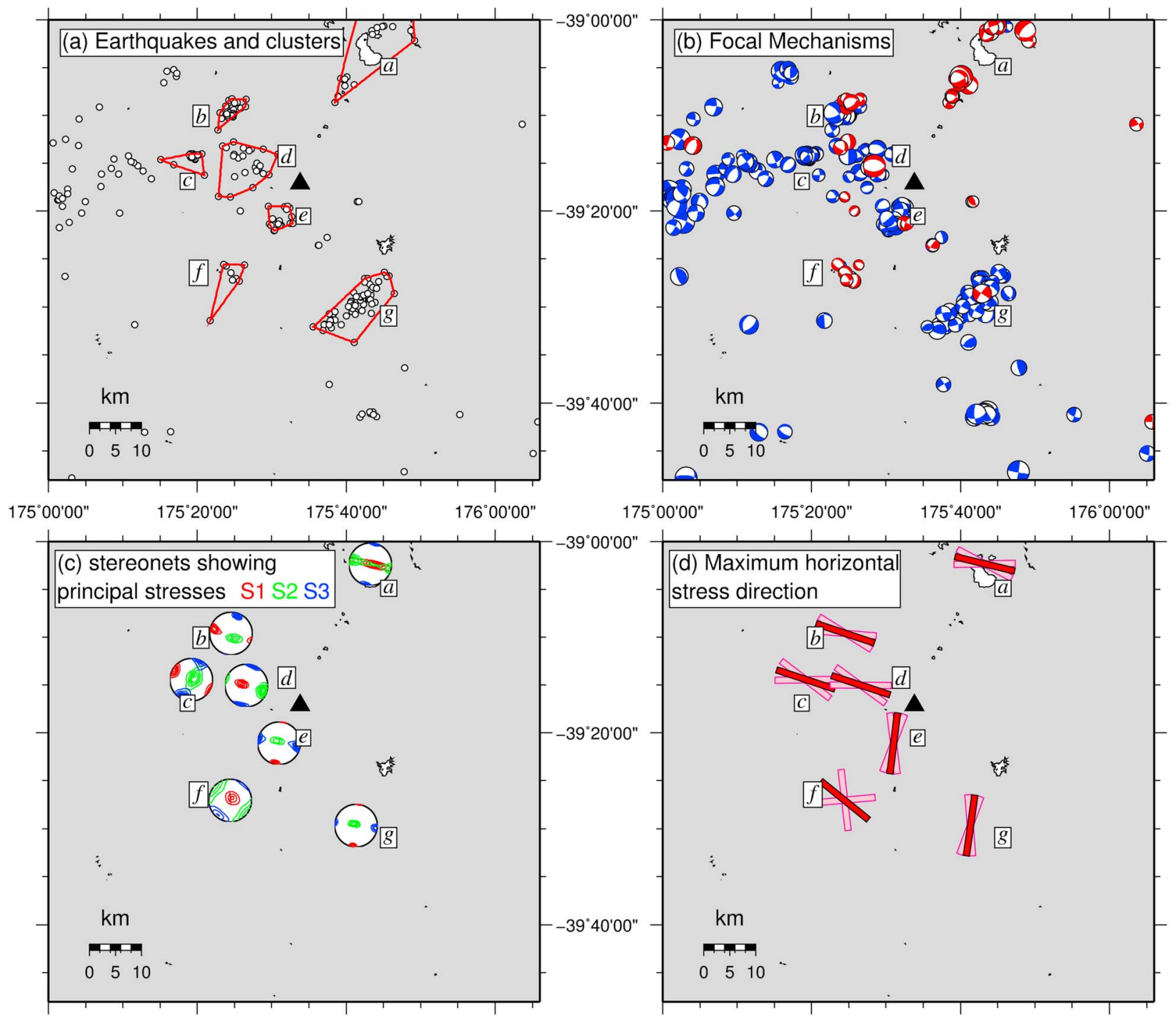

Figure 3. Steps to calculate $S_{H \max }$ from focal mechanism inversions using the method of Arnold and Townend [2007]. Black triangles indicate the summit of Mt. Ruapehu. (a) White dots show epicenters of earthquakes that have focal mechanism information; red boxes group the earthquakes into seven clusters. (b) Focal mechanisms used in the inversions are after Sherburn et al. [2009]. Blue indicates hypocenter is deeper than $8 \mathrm{~km}$, and red is shallower than $8 \mathrm{~km}$. (c) Stereonets showing principal stresses with $S_{1}$ in red, $S_{2}$ in green and $S_{3}$ in blue. (d) $S_{H \max }$ estimations with $80 \%$ confidence interval in pink.

northernmost of which was in our zone 2 (cluster $e$ ) and gave $S_{H \max }^{f o c a l}=007 \pm 14^{\circ}$. The resulting cluster in zone 3 (cluster $f$ ) displays a normal faulting regime with $S_{H \max }^{\text {focal }}$ of $129 \pm 44^{\circ}$, which is sub-parallel to the faults in this zone (Figure 2a), although only eight focal mechanisms were used in the inversion and the errors are large (Table 1). There were enough earthquakes in cluster $g$ (zone 4, the Waiouru swarm) to subdivide the cluster, however all subsets of earthquakes

Table 1. Comparison of Fault Strike, Metamorphic Fabric, Maximum Horizontal Stress From Focal Mechanism Inversions and Fast Polarization From Shear Wave Splitting Results

\begin{tabular}{|c|c|c|c|c|c|c|c|c|c|c|}
\hline Cluster & $\begin{array}{l}\text { Fault } \\
\text { Zone }\end{array}$ & $\begin{array}{c}\text { Fault } \\
\text { Strike (deg) }\end{array}$ & $\begin{array}{c}\text { Metamorphic } \\
\text { Fabric (deg) }\end{array}$ & $\begin{array}{l}\text { Latitude } \\
\text { (deg) }\end{array}$ & $\begin{array}{l}\text { Longitude } \\
\text { (deg) }\end{array}$ & \#FM & $\begin{array}{r}S_{H \max }^{\text {focal }} \\
\text { (deg) }\end{array}$ & $\begin{array}{c}\text { MOE } \\
(80 \%, \text { deg })\end{array}$ & $\phi(\operatorname{deg})$ & $\begin{array}{c}\text { Standard } \\
\text { Deviation (deg) }\end{array}$ \\
\hline$a$ & 1 & 30 & & -39.0391 & 175.7210 & 26 & 103.7 & 14.6 & -5.9 & 21.6 \\
\hline$b$ & $1+2$ & $30+10$ & & -39.1600 & 175.4091 & 32 & 108.5 & 13.73 & 26.1 & 23.1 \\
\hline$c$ & 2 & 10 & & -39.2407 & 175.3203 & 17 & 108.4 & 19.19 & 82.4 & 13.7 \\
\hline$d$ & 2 & 10 & & -39.2507 & 175.4436 & 24 & 108.4 & 17.79 & -26.2 & 13.1 \\
\hline$e$ & 2 & 10 & & -39.3513 & 175.5166 & 24 & 7.0 & 13.9 & 4.5 & 22.6 \\
\hline$f$ & 3 & $090-105$ & & -39.4508 & 175.4074 & 8 & 129.2 & 44.21 & 23.5 & 9.1 \\
\hline$g$ & 4 & $030-045$ & $030-045$ & -39.4945 & 175.6890 & 54 & 7.7 & 12.3 & 14.3 & 7.0 \\
\hline
\end{tabular}


(divided by time, depth, spatially and randomly) yielded the same result to within errors; $S_{H \max }^{\text {focal }}$ of $008 \pm 12^{\circ}$, which was very similar to that of cluster $e$ in zone 2 .

\section{Data}

[14] The Spatial Anisotropy Deployment At Ruapehu (SADAR) project consisted of 13 broadband and three shortperiod temporary three-component seismometers, deployed around Mt. Ruapehu to complement the permanent network of three broadband and 12 short-period three-component seismometers (http://www.geonet.org.nz, GeoNet, last accessed 17 April 2011) (Figure 1). A separate temporary deployment of 3 three-component broadband seismometers around Mt. Ngauruhoe took place in January and February 2008 (A. D. Jolly et al., A new source process for evolving repetitious earthquakes at Ngauruhoe volcano, New Zealand, manuscript in preparation, 2011), the data from which are included in the combined data set with data from the permanent network and the SADAR stations. The SADAR stations were deployed throughout 2008 and during that time recorded 1978 local earthquakes, as small as magnitude 1.0, that were also recorded at the permanent sites and routinely located for the national New Zealand catalog. Of these, 929 had impulsive $\mathrm{S}$ wave arrivals and displayed shear wave splitting at at least one station. More details about the seismic stations used in this analysis are listed in Table S2.

[15] Figure 1 shows the catalog hypocenters of the recorded seismicity (http://www.geonet.org.nz, GeoNet, last accessed 17 April 2011). Hypocenters are routinely calculated by GeoNet and have typical errors on the order of $0.01^{\circ}$ horizontally and $2 \mathrm{~km}$ vertically. The earthquakes tend to occur in three main clusters. The majority of the earthquakes occur to the south-east of Mt. Ruapehu (fault zone 4), around the village of Waiouru and this group of earthquakes is referred to hereafter as the Waiouru swarm (earthquake cluster $g$ ). Many earthquakes also occur to the north-west of the mountain (clusters $b, c$ and $d$ ): these have been referred to in previous studies by several names including the National Park swarm [Sherburn and White, 2006],Raurimu swarm [Reyners, 2010] and Erua swarm [Keats et al., 2011] after features and villages local to the earthquakes. Here we adopt the term Erua swarm as Erua village is directly over the center of the swarm and, even though the Raurimu fault passes through the swarm, we find no evidence that the earthquakes are directly related to the fault. The cluster of earthquakes to the north-west continues in a line to the west. This is the so-called Taranaki-Ruapehu Line (TRL) [Sherburn and White, 2006; Stern et al., 2006]. The third cluster ( $a$ ) near Mt. Tongariro to the north-east is smaller and somewhat shallower $(<8 \mathrm{~km})$ than the other two but nevertheless is important in this study and is referred to as the Tongariro swarm. Deep $(>50 \mathrm{~km})$ earthquakes originate from the subducted slab and Figure 1 illustrates the deepening of these earthquakes, and hence the subducted slab, to the northwest.

\section{Method}

\subsection{Shear Wave Splitting}

[16] We use the automatic shear wave splitting method of Savage et al. [2010a], which incorporates the Silver and Chan [1991] algorithm for calculating shear wave splitting using a grid-search inversion over the azimuth of the fast polarization direction $\phi$ and delay time $\delta$ t, for a given time window, and Teanby et al.'s [2004] SPLIT code, which conducts cluster analysis over a range of time windows to find the most stable result. The optimum filter is identified based on a product of the signal-to-noise ratio and bandwidth, and time window extremes are based on the dominant frequency of the first three seconds of the S waveform. In addition, the Savage et al. [2010a] method grades or rejects the splitting parameters chosen by the cluster analysis based on the distribution of clusters in order to mitigate cycle skipping and ambiguous results. Figures S1 and S2 display examples of different graded measurements used in this study. Uncertainties $\left(\sigma_{d}\right)$ are calculated by finding the $95 \%$ confidence interval for the optimum values of $\phi$ and $\delta$ t after conducting an $F$ test for the chosen time window [Silver and Chan, 1991]. The method requires no input parameters, and the only manual step is determining the $\mathrm{S}$ arrival time. The incidence angle of each ray at each station is calculated using the TauP Toolkit [Crotwell et al., 1999] with the 1-D velocity model of Latter [1981] for the Ruapehu region. Rays with incidence angles greater than $35^{\circ}$ from vertical are not included in the analyses as these lie outside the shear wave window [Nuttli, 1961] and S-P conversions at the surface could contaminate the waveforms. We observe that the steep velocity gradient in the top $0.5 \mathrm{~km}$ ensures that the majority of the local earthquakes recorded fulfill this criteria. The initial polarizations of the incoming waves are calculated as part of the algorithm, such that applying the calculated splitting parameters returns the waves to their unsplit state. Results from the shear wave splitting analysis that gave $\phi$ to within $20^{\circ}$ of the polarization of the incoming wave were considered null results [Peng and Ben-Zion, 2004] and not included in the interpretation (see Figure S3 for an example). Nulls signify that no splitting was reliably detected [Silver and Chan, 1991], rendering the corresponding value of $\delta$ t meaningless and giving $\phi$ with a $90^{\circ}$ ambiguity. The $\phi$ results are often plotted as rose diagrams (circular histograms) at the station where the measurements were recorded (e.g., Figure 4).

\subsection{Delay Time Tomography}

[17] In order to constrain the locations of high anisotropy, a two-dimensional tomographic inversion was conducted on the delay time $(\delta \mathrm{t})$ estimates from the shear wave splitting analysis to obtain the strength of anisotropy (the amount of splitting in seconds, measured per $\mathrm{km}$ ) in each of the grid blocks. We assume that the shear wave splitting delay times are accumulated along the raypath [e.g., Crampin, 1991; Zhang et al., 2007] and that the total delay time is simply the sum of the delay times for each grid block that the ray traverses.

$$
\delta \mathrm{t}_{r}=\sum_{b=1}^{n}\left(s_{b} \times L_{r b}\right)
$$

Here $\delta \mathrm{t}_{r}$ is the measured delay time of the ray $r ; s_{b}$ is the strength of anisotropy per grid block, and $L_{r b}$ is the length of the raypath within each of the $n$ blocks. The assumption that $\delta \mathrm{t}$ is simply additive is a simplification of a non-linear relationship between heterogeneous anisotropy and the observed apparent $\delta \mathrm{t}$ at the surface. However, it gives a first-order approximation to the heterogeneous anisotropic structure of regions of strong and weak anisotropy. 


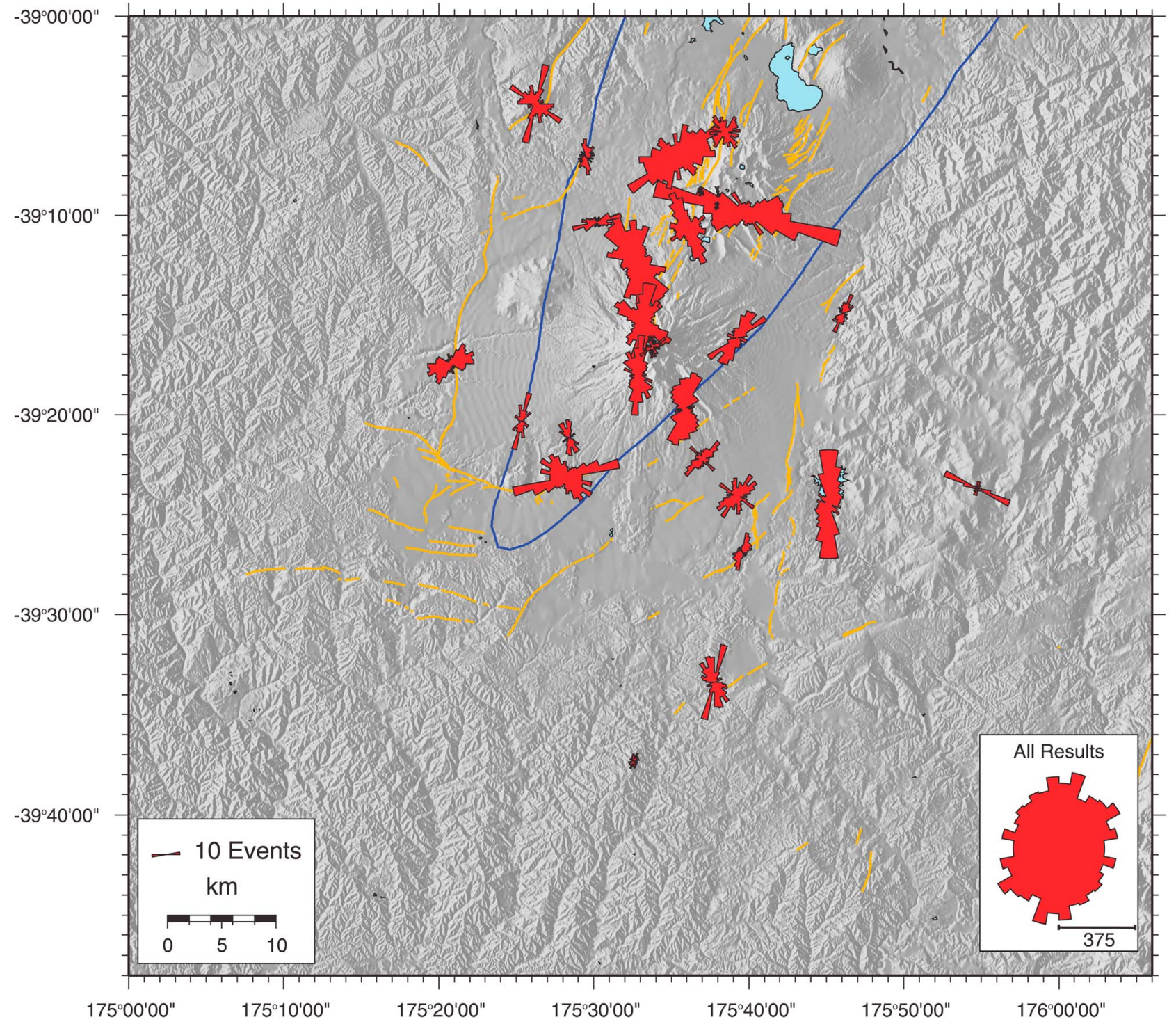

Figure 4. Rose diagrams of fast polarization of split shear waves from automated method [Savage et al., 2010a]. Rose diagrams are plotted on the station at which the observations were made and are scaled according to the number of measurements so that the area of each bar, rather than the length, is proportional to the number of measurements. Note the bimodal forms of some of the rose diagrams. Orange lines are known faults (from the NZ Active Faults Database of GNS [after Villamor and Berryman, 2006]), blue line is the outline of the TVZ [after Wilson et al., 1995].

[18] Other authors [Crampin, 1994; Sayers and Kachanov, 1995] have calculated crack density to characterize the strength of anisotropy, but the possibility of anisotropy in our study area being caused by effects other than fluid-filled cracks means that the anisotropy cannot be interpreted solely in terms of an idealized crack model. To accomplish the inversion, we first gridded the study region using a quad-tree gridding system [Townend and Zoback, 2001, 2004] and a minimum block size of $5 \mathrm{~km}$ square, with each grid block having between 20 and 65 raypaths passing through it. These parameters were chosen to minimize the residuals from the tomographic inversion, while ensuring that each block contained enough data to give a reliable mean when the $\phi$ measurements of the rays intersecting it were averaged for the analysis in section 3.3. The results obtained using variations of these parameters are listed in Table S3. The quad-tree gridding method iteratively analyzes each block; more than 65 raypaths passing through a block results in the block being subdivided further, fewer than 20 raypaths means that the block is excluded from the analysis. The gridding continues until all of the blocks fulfill these criteria by either having between 20 and 65 rays passing through them, or by having been divided until it has the minimum size of $5 \mathrm{~km}$ square. Figure 5 displays the rays and 145 grid blocks, 121 of which were used for the analysis.

[19] We used a medium-scale optimization inversion function $(l s q l i n)$ in Matlab, which uses an active set method 


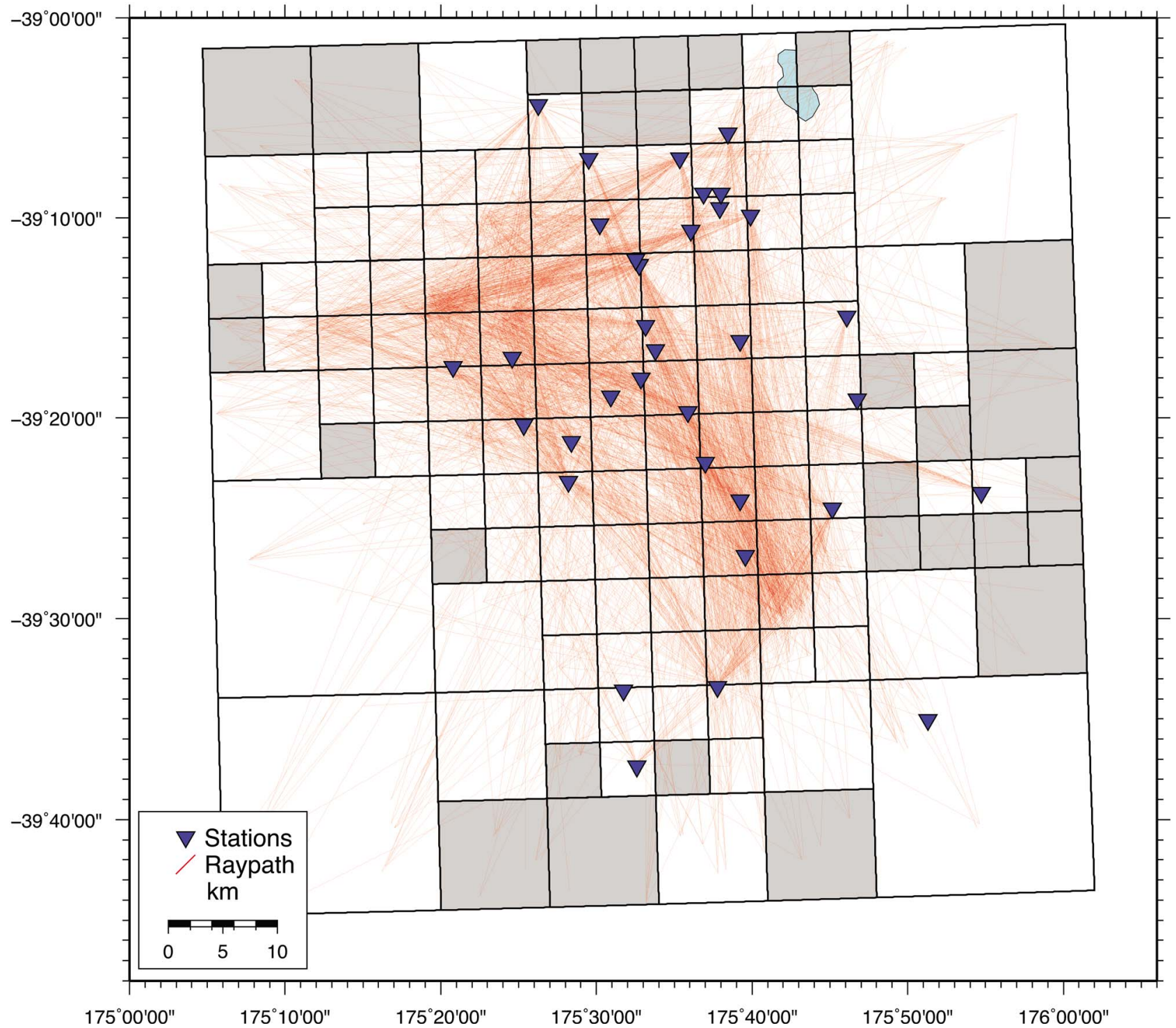

Figure 5. Region of analysis divided into grid blocks using quadtree gridding. Red lines show raypaths, and blue inverted triangles are seismic stations. Criteria for gridding were that there be between 65 and 20 raypaths passing through each box, with a minimum box size of $5 \mathrm{~km}$. This resulted in 149 blocks, 121 of which are used in the analysis. Shaded boxes show those not used. The grid is oriented at a slight angle from north because the grid was constructed using the New Zealand Map Grid (NZMG) coordinate system and plotted in latitude and longitude.

similar to that described by Gill et al. [1981]. This algorithm determines a feasible initial solution by first solving the linear least squares problem, then converges on a final solution iteratively subject to bounding constraints. The active set refers to the elements that remain within the boundary constraints with each iteration. The constraints were set so that the minimum strength could not be below $0 \mathrm{~s} / \mathrm{km}$ and that the maximum could not exceed the maximum $\delta$ t observed for a raypath applied to one block length, i.e., $\delta \mathrm{t}_{\max } / L_{\min (b)}$ where $L_{\min (b)}$ is the width of the smallest block from the quad-tree gridding. The data were weighted so that the problem becomes (in matrix notation)

$$
\mathbf{G}^{T} \mathbf{C}^{-1} \underline{d}=\left(\mathbf{G}^{T} \mathbf{C}^{-1} \mathbf{G}\right) \underline{m}
$$

Here $\mathbf{G}$ is the design matrix constructed by finding the distance that each ray traverses each block, i.e., from $L_{r b}$; $\underline{d}$ is a vector containing the $\delta$ t measurements of each ray; $m$ is the model solution containing the strength of anisotropy (the amount of splitting) per block. The errors can be split into the measurement errors and the inversion errors, which originate from the scale of the strength variation of the model. We therefore construct the error covariance matrix, $\mathbf{C}$, with diagonal components

$$
C_{i i}=\sigma_{d}^{2}(i)+L_{b}^{2} \times \tilde{\sigma}_{m}^{2} \times n_{b}(i) / n
$$

and constant off-diagonals with values:

$$
C_{i j}=\tilde{\sigma}_{m}^{2} \times L_{b}^{2} / n^{2}
$$




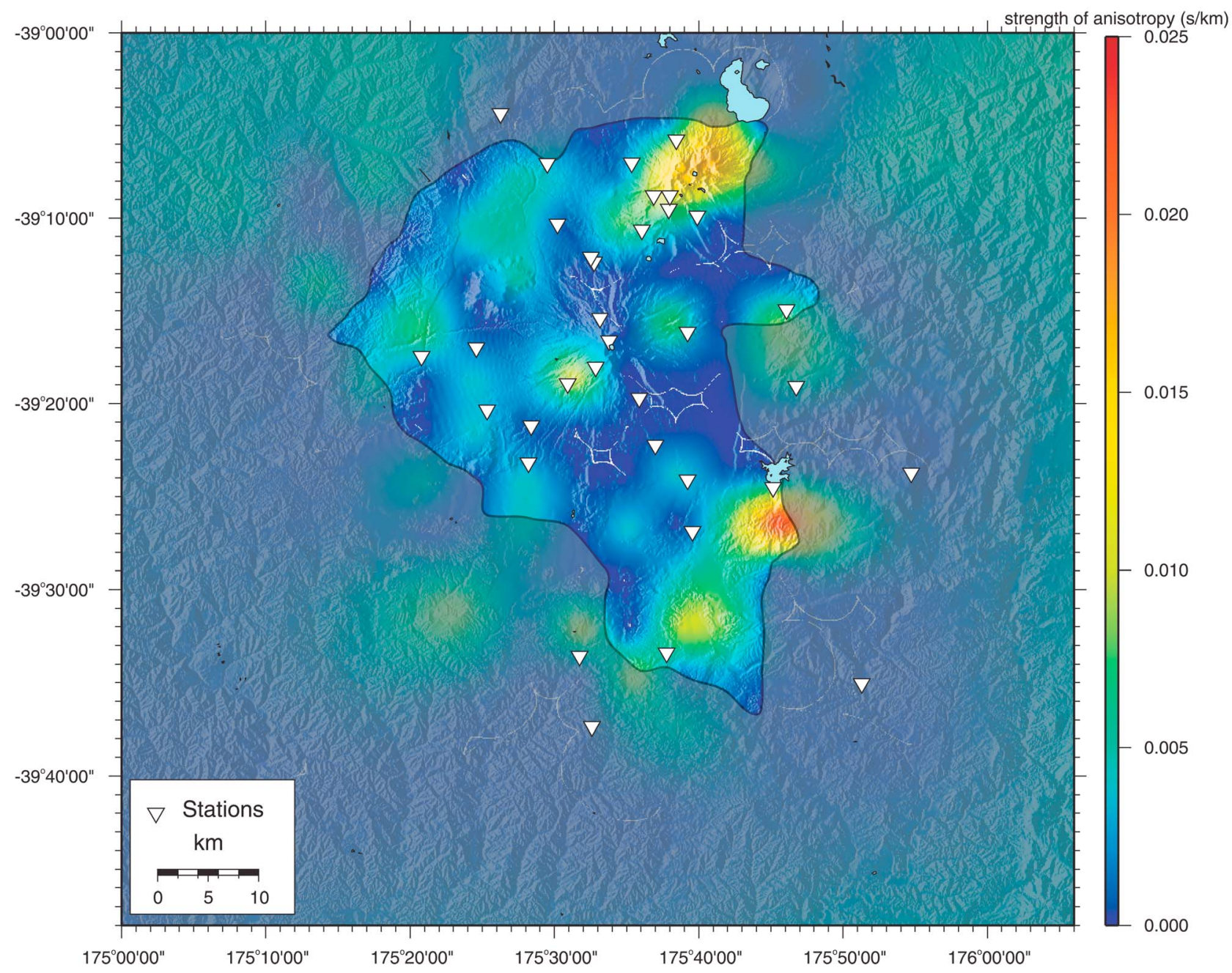

Figure 6. Delay time tomography from the inversion of data. Warm colors indicate strong anisotropy, the shaded area shows the limit of statistical significance calculated from the model variance matrix, and white inverted triangles are seismic stations.

Here $\sigma_{d}^{2}(i)$ is the squared standard error of the $i$ th measurement, $L_{b}$ is the length scale of the boxes, $n_{b}(i)$ is the number of boxes the $i$ th ray passes through and $\tilde{\sigma}_{m}^{2}$ is the mean of the variance of the result when the data are weighted as $1 / \sigma_{d}(i)$. To test the scale of the effect that each section of the ray has on other sections, $n$ is an arbitrary number of sections to further divide the portions of each ray in each box. We conducted the inversion with various values of $n$, ranging from 1 to 1000 and found the inversion results to be relatively insensitive to the weighting. The results are presented using $n=100$ and output parameters for different values of $n$ are listed in Table S3. We performed a checkerboard test to assess where structures may be retrieved. The checkerboard test was carried out by constructing the checkerboard model vector $\underline{m}_{C B}$ using a regular grid with blocks given alternating anisotropy strength values of $0.01 \mathrm{~km} / \mathrm{s}$ and $0.02 \mathrm{~km} / \mathrm{s}$, and adding random noise drawn from a standard normal distribution. Synthetic $\delta \mathrm{t}$ measurements were calculated by the linear multiplication:

$$
\underline{d}_{C B}=\mathbf{G}_{C B} \underline{m}_{C B}
$$

The inversion was then carried out using the quad-tree grid as described above. Figure 6 displays the inversion results and Figure S4 displays the results from a checkerboard test.

[20] The resolution matrix was found to be the identity matrix because the problem is over-constrained due to the design of the grid, namely that each block should have more than 20 rays passing through it in order to obtain a reliable average $\phi$ per block (see section 3.3). The limit of statistical significance illustrated in Figures 6 and S4 was constructed by finding the contour where the $\log$ of the standard deviation (square-root of the diagonal elements of the model variance matrix) was -5.5 (see Figure S5 for contours of $\left.\sigma_{m}\right)$. The value of $\log _{10} \sigma_{m}(i i)=-5.5$ was chosen because it encompassed most of the grid blocks with more than 20 rays, and included the features from the checkerboard test that were best reconstructed. It can be seen in Figure S5 that a different choice of cut-off would give a different limit of statistical significance and that the choice given here is a conservative estimate in that there are features of the checkerboard that are recreated outside of this limit. 


\subsection{Spatial Averaging}

[21] We produced spatial averages of splitting parameters as a first-order approximation to the heterogeneous anisotropic structure [Audoine et al., 2004]. To construct the map of spatial averages in $\phi$, the $\phi$ values were weighted and assigned to each grid block that each ray passed through using the quad-tree gridding from section 3.2. The rose diagrams of the $\phi$ values are plotted and the mean direction (computed using circular statistics) from each grid block is plotted only when the standard deviation of the data is less than $30^{\circ}$ and the standard error of the mean is less than $10^{\circ}$. These criteria enable us to eliminate those blocks exhibiting large scatter or more than one mode. Several weighting schemes were tested and are displayed in Figure S6: FigureS6a corresponds to no weighting function, and Figures S6b and S6c correspond to the situations in which the $\phi$ values are weighted by $1 / d$ and $1 / d^{2}$, where $d$ is the distance of the grid block from the station [Audoine et al., 2004]. This weighting scheme was designed to account for the fact that the value of $\phi$ will be influenced by a greater amount by anisotropic media later in the path [Rumpker and Silver, 2000; Nistala and McMechan, 2005]. Figure S6d displays weighting for the regions of high anisotropy determined by $\delta \mathrm{t}$ tomography, described in section 3.2. To obtain this weighting the anisotropy strength profile along each ray was normalized by the $\delta$ t measurement for the particular raypath and used as the weighting function, $w$ :

$$
w_{r b}=\frac{s_{b}}{\delta t_{r}}
$$

Here $r$ signifies the passing ray and $b$ signifies the block in question so that the average fast direction for $n$ rays passing through the block, $\bar{\phi}_{b}$, is:

$$
\bar{\phi}_{b}=\tan ^{-1} 2\left(\frac{\sum_{r=1}^{n} \sin \phi_{r} \times w_{r b}}{\sum_{r=1}^{n} w_{r b}}, \frac{\sum_{r=1}^{n} \cos \phi_{r} \times w_{r b}}{\sum_{r=1}^{n} w_{r b}}\right)
$$

The spatial averaging using $1 / \mathrm{d}^{2}$ weighting (Figure S6c) produces the least scatter and the most means with standard error and standard deviation to within the threshold values stated in section 3.3. Spatial averaging using $1 / d^{2}$ weighting functions yielded 88 measurements within the thresholds, whereas 64 measurements were produced by averaging with no weighting function, 75 were produced with $1 / d$, and 73 were produced using the tomography weighting functions. Therefore we will subsequently analyze the map of spatial averaging using $1 / \mathrm{d}^{2}$ weighting functions (Figure 7 ).

\section{Results}

\subsection{Shear Wave Splitting}

[22] Figure 4 displays rose diagrams of the fast polarizations for earthquakes recorded in 2008, plotted at the station at which they were recorded and scaled according to how many measurements were obtained. Table S4 includes information about how many events were used at each station and Figure S7 displays results from just the shallow
$(<30 \mathrm{~km})$ and deep $(>50 \mathrm{~km})$ earthquakes separately. The vast majority of the earthquakes fall into the shallow category and, while there are small differences between the results from the shallow and deep events at some stations, these results don't influence the overall analysis. The automatic shear wave splitting algorithm chooses a filter based on the dominant frequency of the waveforms and the bandwidth. We do not observe a systematic difference in the chosen filter as a function of depth. We also do not see a systematic increase in delay time for the deep events. These observations suggest that at the frequencies chosen (predominantly $1-8 \mathrm{~Hz}$ ) the anisotropy that we are measuring is crustal in origin, although upper mantle anisotropy could be affecting the waveforms at lower frequencies. We conclude that the following analysis benefits more from the inclusion of all of the data, thus increasing the data set, than it would from the exclusion of deep earthquakes. Therefore both deep and shallow earthquakes have been included throughout.

[23] In order to ensure that there were no strong temporal changes in anisotropy during the SADAR experiment, we performed a temporal averaging analysis similar to that used by Savage et al. [2010b]. Figure 8 shows $\phi$ and $\delta$ t results throughout 2008 for a subset of the stations. Station TUVZ is on the east flank of Mt. Ruapehu and has been used in previous studies to demonstrate temporal changes in anisotropy [Gerst and Savage, 2004], in attenuation [Titzschkau et al., 2010] and in cross-correlation functions from ambient seismic noise [Mordret et al., 2010]. Station TRVZ is on the south-west flank of the volcano, close to the summit and was also used by Gerst and Savage [2004]. Stations OTVZ, MOVZ and PKVZ are further away from the summit of Mt. Ruapehu at different azimuths from the volcano. Each of these stations is close to one of the main clusters of earthquakes displayed in Figure 1 but each records earthquakes from all three clusters. Figure 8 shows that there are small, insignificant variations in the $\phi$ and $\delta \mathrm{t}$ averages throughout 2008 at some of the stations but that these variations are uncorrelated. We therefore treat all the data as time independent.

[24] Some of the rose diagrams in Figure 4 display directions with very little scatter and one strong modal orientation. Others, however, display more scatter or bimodal forms. Further analysis of the shear wave splitting results from station TWVZ (Figure 9a) suggests that the two main modes of $\phi$ are caused by measurements from earthquakes with two dominant back azimuths. The two back azimuths are consistent with the distribution of seismicity displayed in Figure 1. There is also a third back azimuth associated with the third cluster of earthquakes that gives a discrete $\phi$, although this isn't obvious from the rose diagram. The two back azimuths from the strong orientations of $\phi$ are less then $050^{\circ}$ apart, suggesting that as the rays approach the station, they traverse similar paths. The path lengths and depths sampled by the rays further from the station are quite different, with more distant earthquakes sampling deeper crust. The two strong orientations of $\phi$ associated with these back azimuths are about $80^{\circ}$ different, suggesting the splitting occurred in the early part of the raypath, further from the station. The same analysis of shear wave splitting results from station WPVZ (Figure 9d) shows that, although the rose diagram doesn't show three clear modes, there is more than one value of $\phi$ caused by more than one back azimuth. 


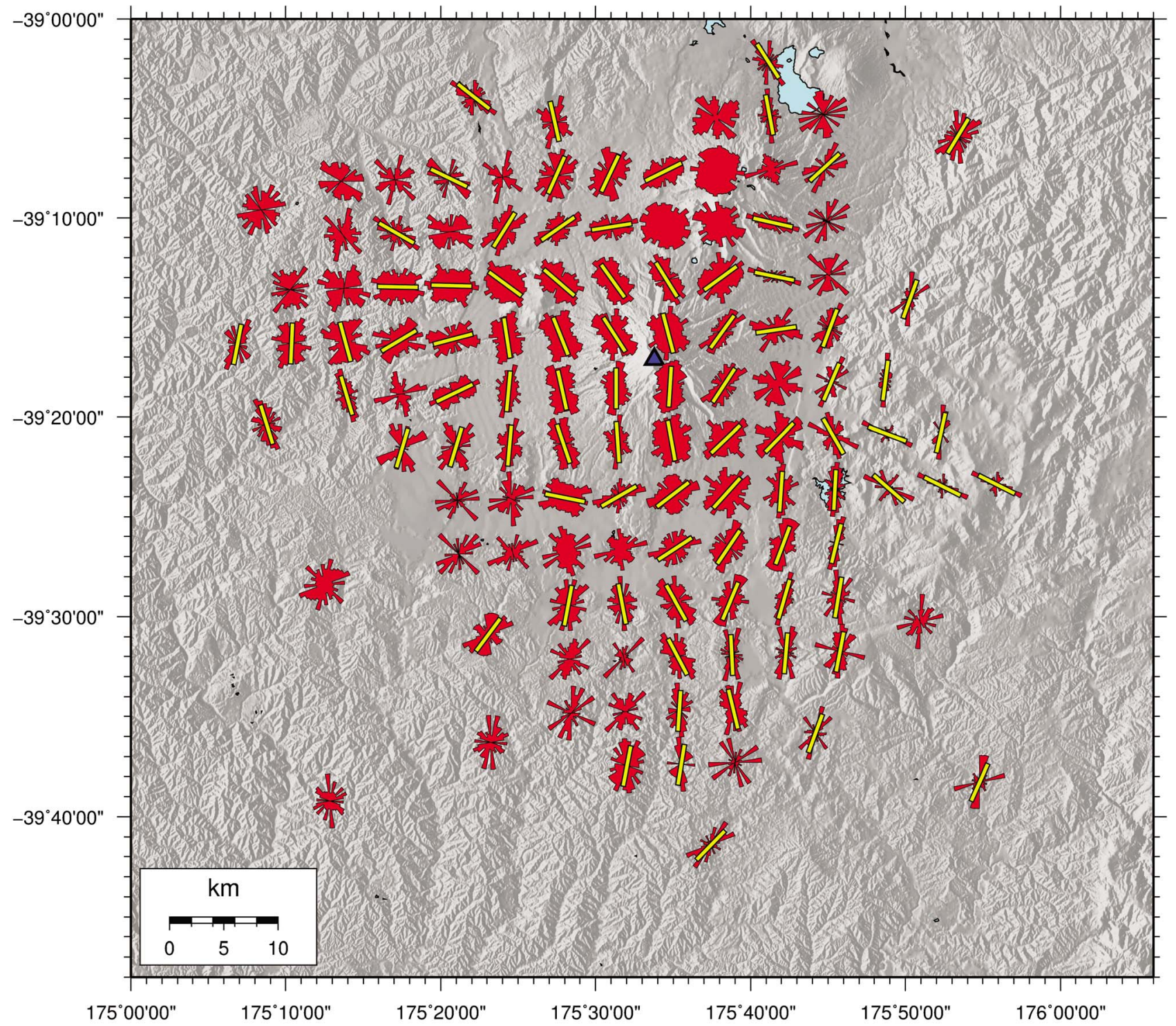

Figure 7. Spatial averages of fast shear wave polarizations from shear wave splitting with weighting inversely proportional to the square of the distance from the station. Red rose diagrams are normalized; yellow bars show mean polarization. Blue triangle indicates the summit of Mt. Ruapehu. Rose diagrams are plotted in the center of each grid block, and those grid blocks with less data than the threshold are not plotted. Grid blocks with a standard deviation larger than $30^{\circ}$ and standard error larger than $10^{\circ}$ do not have the mean plotted.

This back azimuthal dependence suggests that the $\phi$ value obtained from shear wave splitting analysis is highly dependent upon the path that the ray takes, which has also been found in other regions by Zinke and Zoback [2000], Liu et al. [2004] and Johnson et al. [2010]. Furthermore, this suggests that the anisotropy is not uniform throughout the crust in the study region, as is observed for mantle anisotropy [Greve et al., 2008] and that averaging $\phi$ over the whole region [Gerst and Savage, 2004] may not be appropriate. Azimuthal analysis of data from all of the stations is in Figures S8 and S9. The dense network of seismometers means that we can locate the regions with different anisotropy with more certainty. To do this we carry out spatial averaging of the measurements (sections 3.2 and 3.3).

\subsection{Spatial Averaging}

[25] There are some strong, but complex, patterns that are visible in the mean $\phi$ values in Figure 7 . When all of the measurements are combined they have a mean of $013^{\circ}$ (from Figure 4), which correlates with most $S_{H \max }^{\text {focal }}$ estimations for the Ruapehu region (Table S1) and also regional anisotropy from SKS $\left(007-066^{\circ}\right)$ and Pn studies [Greve et al., 2008; Seward et al., 2009]. This direction is sub-parallel to the trench caused by the Pacific Plate subducting beneath the Australian Plate striking at $015^{\circ}$ [Wood and Davy, 1994], and the strike of structures in the region such as the line of volcanoes that make up the TVZ and bounding faults $(010$ $030^{\circ}$ [Rowland and Sibson, 2001; Villamor and Berryman, 2006]). However, the overall distribution does not have a 


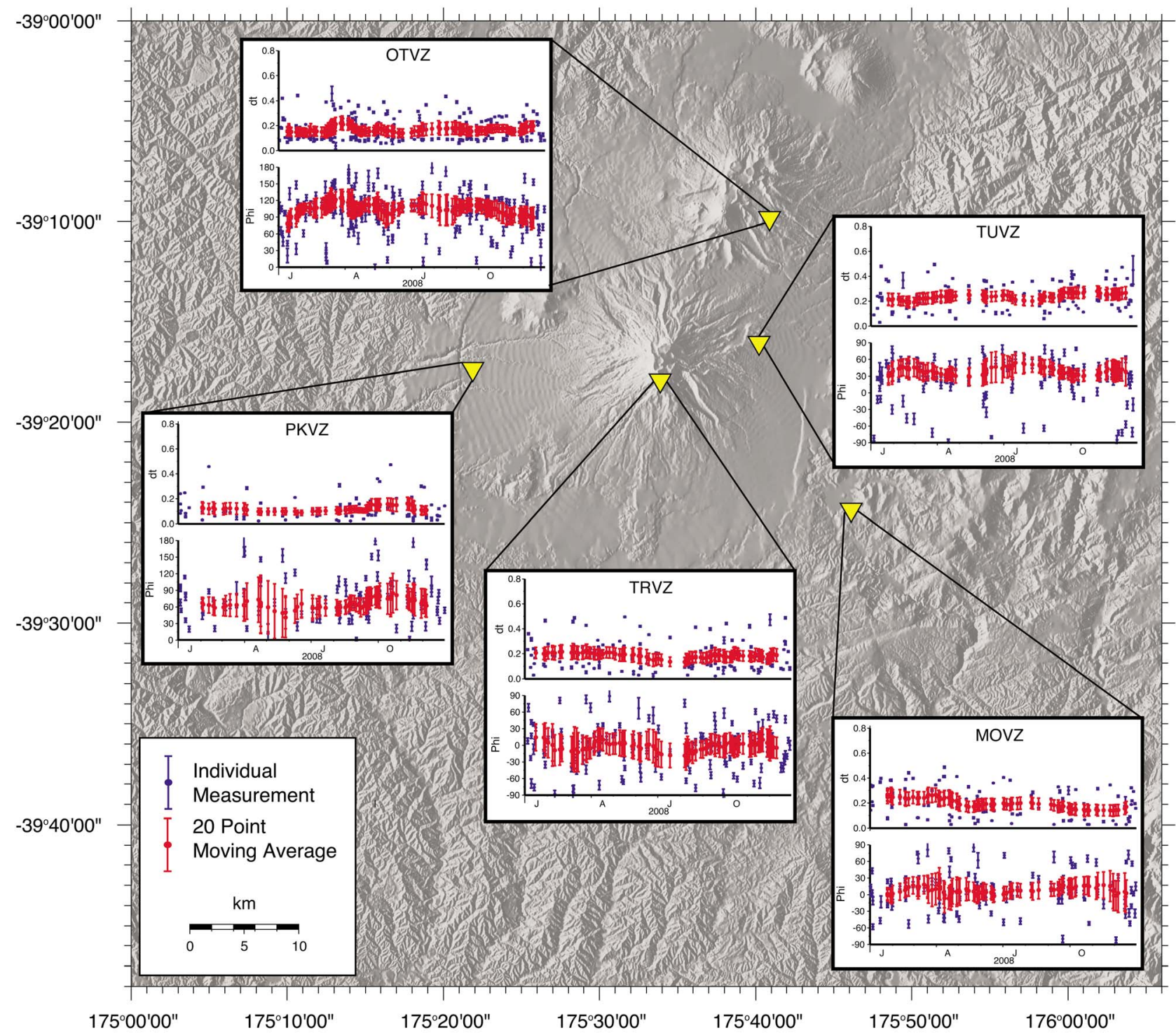

Figure 8. Shear wave splitting data for earthquakes throughout 2008 recorded at five stations. Scattergraphs show individual measurements (blue) with error bars indicating the $95 \%$ confidence interval for each measurement and a 20 point moving average (red) with error bars indicating the standard error of the mean. The top graph of each panel shows delay time results, and the bottom graphs show fast orientation results.

single strong mode, and we observe a greater degree of heterogeneity when we examine the smaller scale detail. Only to the south-east and north-east of the study region is the NNE-SSW trend dominant. South of Mt. Ruapehu (around $\left.-175^{\circ} 30^{\prime}-39^{\circ} 20^{\prime}\right)$ the trend is more north-south, and to the north-west of the volcano (around $-175^{\circ} 20^{\prime}-39^{\circ} 10^{\prime}$ ) the fast polarizations turn to a more east-west orientation.

\subsection{Delay Time Tomography}

[26] Figure 6 displays the inversion results with several interesting features. There is a region of high anisotropy to the north-east of Mt. Ruapehu, which coincides with the location of other volcanoes: Mt. Ngauruhoe and Mt. Tongariro. The region immediately surrounding Mt. Ruapehu does not exhibit high anisotropy. There is a region of high anisotropy to the south-east of the study area, which corresponds to the persistently active Waiouru swarm
(Figure 1) [Hayes et al., 2004]. The Waiouru swarm is a linear feature, which does not have many seismometers, nor earthquakes on its south-east side, resulting in the blocks encompassing the Waiouru swarm appearing less populated with rays to the south-east (Figure 5). However, there are still many crossing rays and rays originating in these blocks so that the results of the checkerboard test (Figure S4) suggest that the region is well resolved.

\section{Interpretation}

[27] It is important to differentiate between stress-induced and structural anisotropy before interpreting shear wave splitting parameters and any time variations observed. Kaneshima [1990], Zinke and Zoback [2000] and Boness and Zoback [2006] were able to distinguish between stressinduced and structure related anisotropy in regions where 


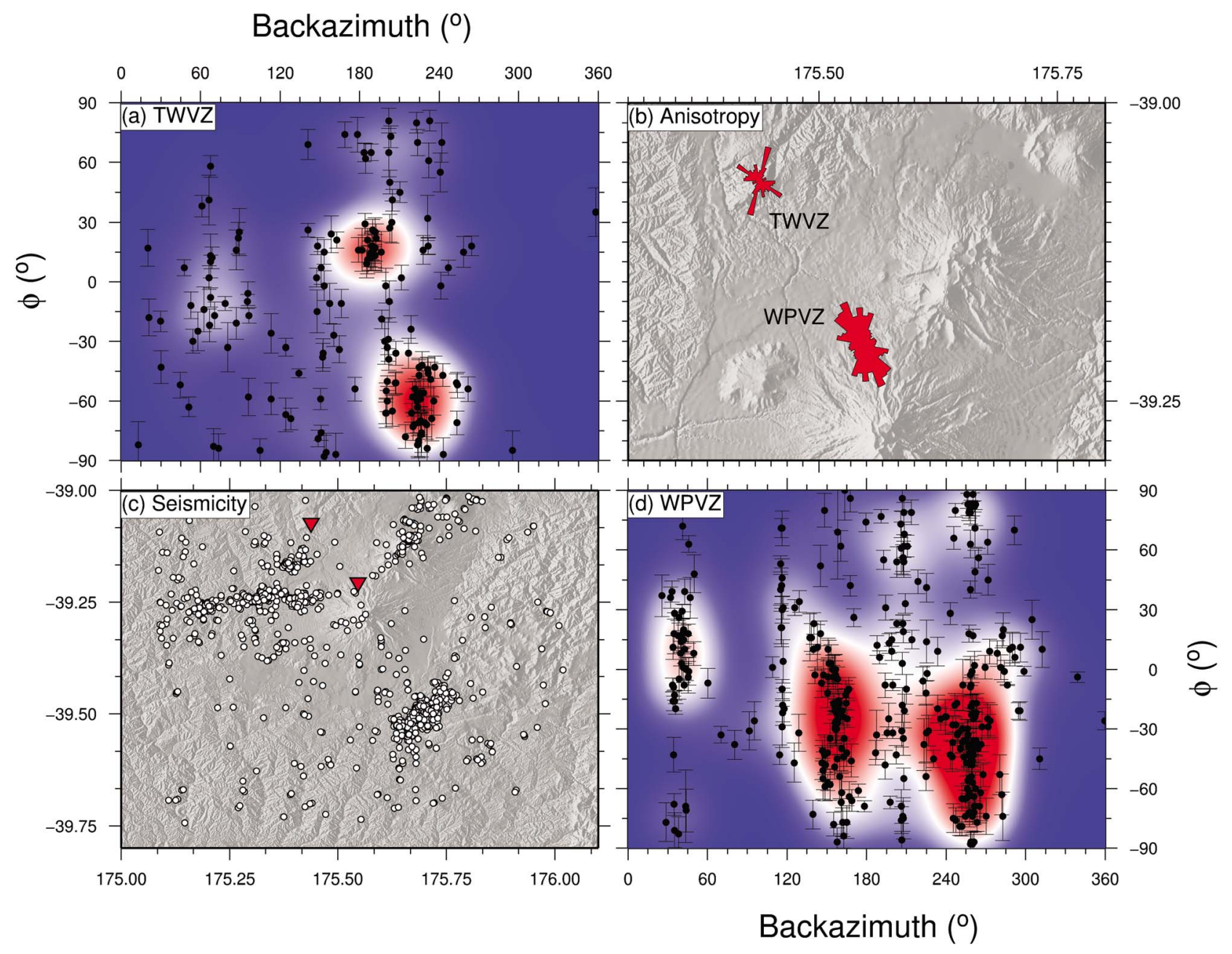

Figure 9. Azimuthal analysis of fast polarization data for stations TWVZ and WPVZ. (a) Back azimuth versus fast polarization plot for TWVZ showing three strong back azimuths giving distinct fast polarizations. Colors represent density of data points. (b) Zoom-in on rose diagrams from Figure 4 for stations TWVZ and WPVZ, showing one bimodal and one linear rose diagram. (c) Map of the area around Mount Ruapehu (from Figure 1). The white circles indicate the catalog locations of the earthquakes in 2008, used in this study. The inverted triangles represent seismometers. (d) Back azimuth versus fast polarization plot for WPVZ showing three strong back azimuths again giving distinct fast polarizations even though these are not obvious from the rose diagram alone.

both the regional stress field and local structures were well known. These are examples where individual shear wave splitting measurements display either stress-induced or structure related anisotropy. The Boness and Zoback [2006] study also found that some stations displayed a mix of polarizations, which could have been from a mix of anisotropy mechanisms or an average of the two.

[28] As crustal stresses change, either locally due to earthquakes, fluid movement, and/or volcanic activity, or regionally due to tectonic movement, the contribution of stress induced microcracks to the anisotropy will change. If the effect of stress induced microcracks on shear wave splitting becomes stronger than that of the structural influences, and the direction of $S_{H \max }$ is different to the strike of the structure, then a rotation of $\phi$ may be observed. This temporal rotation of $\phi$ indicates a change in $S_{H \max }$, and therefore the stress tensor, that could be either directional or magnitudinal. We do not observe a temporal variation in shear wave splitting parameters during this study, however to aid the interpretation of past changes and possible future changes, it is important to create a benchmark.

[29] To determine whether the anisotropy that was observed in 2008 is governed by stress-induced microcracks or structural influences, we use the zones and clusters defined in section 1.3 and Figure 2 and compare the horizontal direction of metamorphic fabric, surficial fault strikes, $S_{H \max }^{f o c a l}$ and $\phi$. The results are listed in Table 1. These different observations all sample different levels within the crust; surficial faults give estimates of $S_{H \max }$ at the surface at the time of faulting and a possible source of anisotropy around the fault plane, seismic source observations give estimates of $S_{H \max }$ at the depth of the earthquake and anisotropy samples the path between the seismic source and the surface. Therefore this 2-D analysis is a first order approximation and 

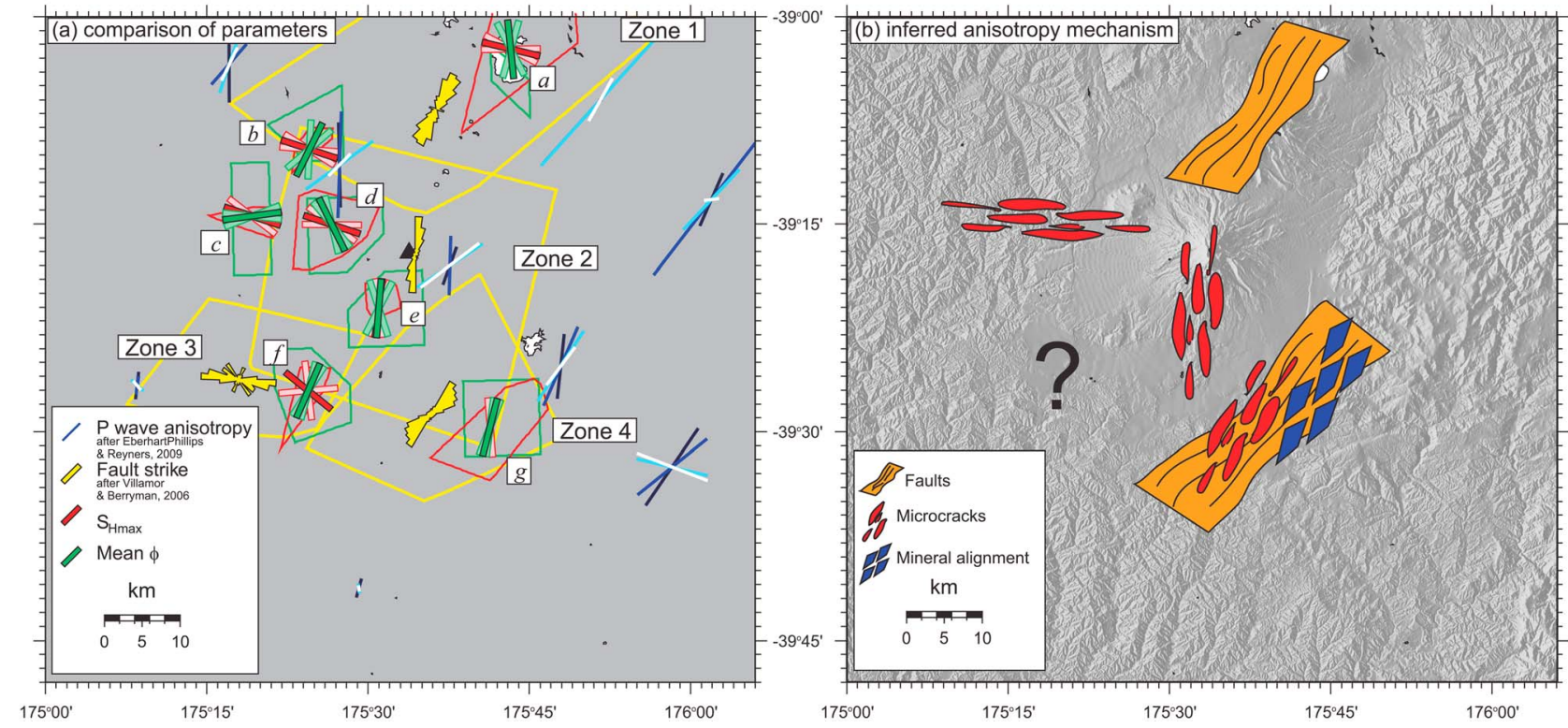

Figure 10. (a) Comparison of fault strikes, $\phi, S_{H \max }$ and fast direction from $\mathrm{P}$ anisotropy tomography. Black triangle indicates the summit of Mt. Ruapehu. Red bars show direction of $S_{H \max }$ from focal mechanism inversions with $80 \%$ confidence interval, and red polygons show clusters of earthquakes used. Green bars show $\phi$ direction with standard error, and green polygons show areas of anisotropy measurements used. Yellow rose diagrams show fault strikes after Villamor and Berryman [2006], and yellow polygons show zones from Figure 2. Blue bars show P wave anisotropy tomography after Eberhart-Phillips and Reyners [2009]. Length of bar indicates strength of anisotropy and color represents depth of modeled anisotropy: white is at $0 \mathrm{~km}$, getting progressively darker through 4, 11 and $18 \mathrm{~km}$ depth (black). (b) Inferred anisotropy mechanisms around Mt. Ruapehu. Anisotropy to the north of Mt. Ruapehu is thought to be controlled by fractures and faults. Anisotropy in to the west and south is thought to be caused by stress-induced microcracks, even though the direction changes. The area to the south-west does not contain enough data to draw conclusions about the mechanism of anisotropy, and anisotropy to the south-east is probably caused by a combination of mineral alignment, stress-induced microcrack alignment, and fractures.

more in depth interpretation could be done with the use of a 3-D tomographic inversion of the shear wave splitting parameters. Figure 10a also shows anisotropy fast azimuth and strength from the $\mathrm{P}$ wave anisotropy tomography of Eberhart-Phillips and Reyners [2009]. The estimates are plotted on the node of the inversion and vary with depth. Comparison of this P wave anisotropy with the stress, structure and shear wave splitting is difficult to quantify due to the coarse grid, however the general agreement is good and we suggest that the $\mathrm{P}$ wave anisotropy fits our data best shallower than about $11 \mathrm{~km}$ depth (light blue Figure 10a). This mid-upper-crustal depth fits with the majority of the raypaths, however, it is deeper than hypothesized models for magma reservoirs [Price et al., 2007] and so anisotropy at depth would probably not be affected by magma induced stresses. Eberhart-Phillips and Reyners [2009] attribute the crustal anisotropy to foliation in schists (east of study area), crustal stresses (southwest of study area) and fracture zones (north of study area).

\subsection{Stress and Structure}

[30] Comparison of stress estimates from our focal mechanism inversions (section 1.4 and Figure 3) and those of Hayes et al. [2004], Sherburn et al. [2009] and Reyners [2010] with Quaternary fault analysis of Villamor and Berryman [2006] (Figure 10) shows that active $S_{H \max }^{\text {focal }}$ often differs from those inferred from surface faults. Clusters $a, b$, $c$ and $d$ display $S_{H \max }^{\text {focal }}$ that is sub-perpendicular to surface faults, whereas $S_{H \max }^{f o c a l}$ for clusters $e, f$ and $g$ align with surface faults.

\subsection{Anisotropy, Stress and Structure}

[31] To easily compare $\phi$ to $S_{H \max }^{\text {focal }}$ and structural influences, we take an average of the shear wave splitting results within each cluster indicated in Figure 2c. These estimates for average $\phi$ were calculated by taking results from the grid blocks within $10 \mathrm{~km}$ of the earthquake cluster centroid (Figure 2b). We have carried out this analysis for the spatial averaging results using $1 / \mathrm{d}^{2}$ weighting functions and the comparisons are displayed in Figure 10a with reference to the clusters defined by earthquake locations, and to the zones of similar fault strike determined by Villamor and Berryman [2006]. A cartoon summary of our interpretations is presented in Figure 10b.

\subsubsection{Cluster $a$}

[32] In the region of dense faulting in zone 1 the observed shear wave splitting is sub-parallel to the fault strikes (Figure 10). The estimate of $S_{H \max }^{\text {focal }}$, which uses earthquakes from the Tongariro swarm, is nearly perpendicular to $\phi$. Therefore in zone 1 (around cluster $a$ ), the observed shear wave splitting is most likely caused by anisotropy from the fault zones rather than stress induced anisotropy. 


\subsubsection{Cluster $b$}

[33] Cluster $b$, at the south-west edge of zone 1, has similar $\phi$ and $S_{H \text { max }}^{\text {focal }}$ to cluster $a$. Even though the faulting is not as dense near cluster $b$, there are still faults with the same orientation (Figure 2) and therefore the inference of structural anisotropy being dominant holds for all of zone 1 (Figure 10b).

\subsubsection{Clusters $c$ and $d$}

[34] $S_{H \max }^{f o c a l}$ for clusters $c$ and $d$ (in the west of zone 2) is approximately perpendicular to the general strike of the structure and $\phi$ correlates well with $S_{\text {Hmax }}^{\text {focal }}$, suggesting that stress induced anisotropy is the cause of shear wave splitting in this region (Figure 10b). Zone 2 is a region of weak fabric and few mapped faults (Figure 2a), so it is not surprising that $\phi$ does not line up well with the structure (Figure 10a).

\subsubsection{Cluster $e$}

[35] Cluster $e$ is located closer to the center of zone 2. In this case $S_{H \max }^{\text {focal }}$ and $\phi$ align with fault strikes for the zone although there are few surficial faults close to the cluster, suggesting that stress is the governing anisotropy mechanism in this part of zone 2 as well (Figure 10b).

\subsubsection{Cluster $f$}

[36] Neither fault strikes, nor the estimate of $S_{H \max }^{\text {focal }}$ in zone 3 correlate with $\phi$ (Figure 10). However, this location is at the edge of our limit of statistical significance described in section 3.2, and there is no information about basement fabric. While $S_{H \max }^{\text {focal }}$ from earthquakes and surface fault strikes are well aligned in zone 3 , the errors on $S_{H \max }^{\text {focal }}$ are large. We cannot draw conclusions about the cause of anisotropy in zone 3 as there is not enough data.

\subsubsection{Cluster $g$}

[37] Our estimate of $S_{H \max }^{\text {focal }}$ using this cluster (the Waiouru swarm) aligns well with estimates of $\phi$. There is also highergrade schist [Beetham and Watters, 1985] striking in the same direction as mapped faults, as mentioned in section 1.3, which also correlates with $\phi$ (Figure 10a). In this case we are unable to distinguish the cause of anisotropy just by looking at the 2008 data as there were no evident changes in stress. If the anisotropy in this region is governed by stressinduced microcracks and there was a rotation in $S_{H \max }$ then a rotation of $\phi$ would be observed. Even if the anisotropy in 2008 was governed by structural influences, if there was a rotation of $S_{H \max }$, there would likely be a change in magnitude of anisotropy as well. If this change in magnitude was large enough to effect the overall anisotropy then a rotation of $\phi$ would still be observed. Past estimates of $S_{H \max }^{\text {focal }}$ for the Waiouru swarm [Hayes et al., 2004; Sherburn et al., 2009] have all been of similar strike so it is unlikely that temporal analysis of shear wave splitting will assist in the identification of the cause of anisotropy.

\subsection{Delay Time Tomography}

[38] The interpretation of the delay time tomography must be considered in conjunction with the limitations of the method. It is designed to create a first-order approximation for regions of strong and weak anisotropy and will therefore not provide accurate absolute values of anisotropy strength. For example, discrete layers of anisotropy can cause the leading shear wave to resplit [e.g., Yardley and Crampin, 1991] and so the observed $\delta \mathrm{t}$ will be that of the last layer; a $90^{\circ}$ change of fast direction between discrete layers can result in destructive interference and an observed $\delta \mathrm{t}$ smaller than that for either layer; or a layer of anisotropy that has its fast direction parallel with the polarization of the incoming wave will not be split, resulting in zero delay time. However, the large volume of data and crossing rays used in this study allow us to interpret the inversion results with reference to the regions of strong and weak anisotropy.

[39] To interpret the tomography of $\delta \mathrm{t}$ and the regions of high anisotropy to the northeast and southeast of Mt. Ruapehu (Figure 6), we examined other evidence in these regions, as with the spatial averaging above. The region of strong anisotropy to the north-east of Mt. Ruapehu is strongest on the north-east flank of Mt. Tongariro, which is the location of the active Ketetahi geothermal field [Risk et al., 2002]. High pore fluid pressures are likely at geothermal fields and there may be some hydrothermal alteration, creating more cracks in the rocks and therefore also higher percentage anisotropy [Lees and $W u, 1999]$. However, in section 5.2 we saw that $S_{H \text { max }}^{\text {focal }}$ was not aligned with $\phi$ in this region and that the area is densely faulted. Therefore, high pore fluid pressures probably do contribute to the high anisotropy by increasing the fractures, but the regional stress is not strong enough to overprint the structural effect.

[40] There is no evidence for high heat flow in the Waiouru region, but the consistently active seismicity suggests fluid movement in a critically loaded fault zone [Hayes et al., 2004]. Therefore, high pore fluid pressures at depth could be creating a strong stress induced anisotropy. The fault zone itself could be contributing to the anisotropy because even though there are fewer mapped faults in this region than in zone 1, the persistent seismicity suggests highly fractured rock at depth. Close to Waiouru Beetham and Watters [1985] also identified a region of higher-grade metamorphic (semi-schistose) rock, which could also be a cause of anisotropy. The combination of these three mechanisms could combine to create a stronger anisotropy (Figure 10b).

\subsection{Modeling}

[41] Petrologic evidence for Mt. Ruapehu suggests that rather than having one main magma reservoir, magma is stored in evolving dikes and sills dispersed throughout the crust [Price et al., 2005]. If these magma pockets are connected then it is possible that magma injection into the system of small chambers could be modeled as a single expanding source, although it is unlikely to completely describe the system. Bryan and Sherburn [1999] suggested that the relatively quiet seismic scenario of the 1995/1996 eruptions reflected an open vent system, high heat flux and a small volume of magma involved in the eruption. An open system and low magma input are not conducive to detecting stress changes through shear wave splitting analysis at stations tens of kilometers away. However, Miller and Savage [2001] and Gerst and Savage [2004] found that shear wave splitting results changed over time, suggesting that the anisotropy was caused by microcracks aligned with timevarying stress, rather than static structure. Therefore, we use the Coulomb stress modeling package of Lin and Stein [2004] and Toda et al. [2005] to model the maximum horizontal stress caused by inflation sources to gauge whether the observed anisotropy could be caused by stress from one or more pressurized magma reservoirs. We carry out the Coulomb modeling with no regional stress as the evidence outlined in section 1.4 suggests that $\left|S_{1}\right|($ vertical $)>\left|S_{2}\right| \approx$ $\left|S_{3}\right|$ and $S_{H \max }$ is only sensitive to differences between $S_{2}$ 


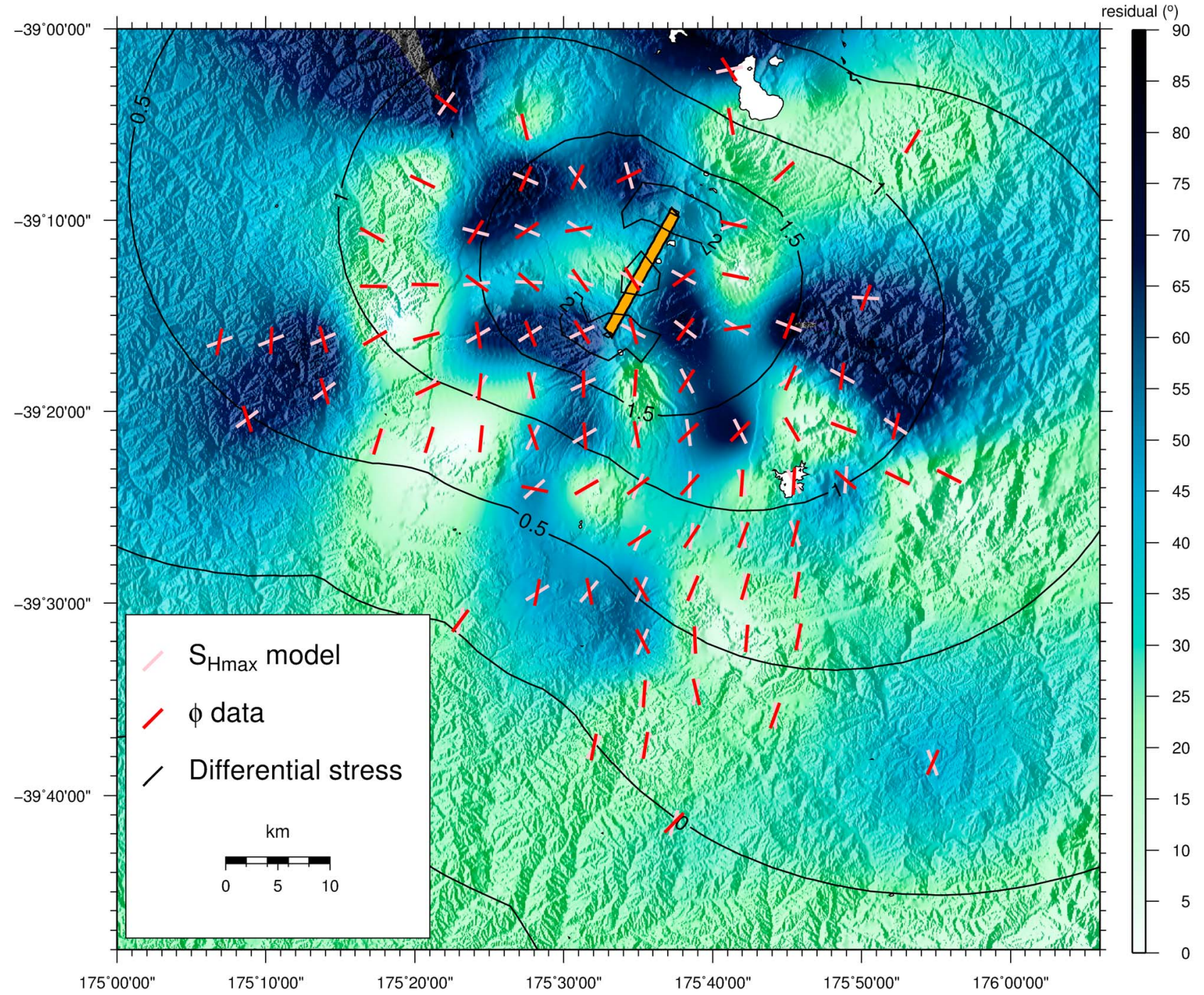

Figure 11. Results from Coulomb modeling of a dike (orange bar) with $0.5 \mathrm{~m}$ of expansion (not to scale). Mean $\phi$ from spatial averaging using $1 / d^{2}$ weighting is in red, and maximum horizontal stress direction as calculated using Coulomb modeling is in pink; contours indicate the strength of the differential stress away from the source, and background colors represent residual between data and model, with dark colors showing higher misfit.

and $S_{3}$. We used dike geometry based on the dike-like feature of low resistivity identified by Ingham et al. [2009], a point source similar to that modeled by Mordret et al. [2010], and a conduit-like source both centered on the volcano. The volume of the sources used was based on the maximum and minimum estimates of eruptive products of the $1995 / 1996$ eruptions, which are $0.005 \mathrm{~km}^{3}$ and $0.01 \mathrm{~km}^{3}$ [Bryan and Sherburn, 1999]. We tested different models (Table S5) because the geometry of the magma reservoir are currently unknown and to possibly constrain the geometry and volume of the subsurface magma.

[42] Figure 11 displays the modeled maximum horizontal stress calculated using the method of Lund and Townend [2007], and the mean $\phi$ in each block from the spatial averaging described in section 4.2, with the residuals shown by the colored background. The pattern of anisotropy, while described well in places by the stress caused by a dike-like magma reservoir, is not consistent in other areas. There could be a major effect from other stress such as that from the topographic loading of the volcanic edifice [Horspool, 2003] and those related to the extension of the TVZ [Villamor and Berryman, 2006; Wallace et al., 2004] that we are unable to account for in this simple model. Table S5 lists the mean fit between the predicted maximum horizontal stress from the different models and the measured $\phi$. The fit is given for the whole study area rather than for specific areas as fault zone 2 includes the majority of the measurements and overlaps with the other zones, and zone 2 is the zone in which stress is inferred to be governing the anisotropy. The dominant feature in the misfit between the data and the model (Figure 11) is an E-W trending line to the north-west of Mt. Ruapehu. This line coincides well with the Taranaki-Ruapehu line (TRL), which is a discontinuity observed in electrical resistivity, gravity, seismic attenuation 
and receiver functions [Stern et al., 2006]. There is also a high rate of crustal seismicity along the line [Sherburn and White, 2005] although there are no mapped surficial features. We suggest that the TRL, as the transition point between different physical rock properties and a gravitational instability, harbors a high stress and possible crustal flow along the line could cause the development of crustal fabrics. Therefore, we attribute the orientation of $\phi$ in the region (Figure 10), and hence the misfit in Figure 11, to the TRL.

[43] Finite element modeling including topography will illuminate the proportion of the stress causing the shear wave splitting observations that originates from topography and what stress effects are from different sources.

\section{Conclusions}

[44] In this paper we have presented shear wave splitting results from a combined data set of two temporary deployments of three-component seismometers and the permanent network. The combined network was denser than any previous studies and so yields a result with a higher resolution of spatial variations in anisotropy. We have used earthquakes that occurred throughout 2008 near Mount Ruapehu and the automated shear wave splitting method of Savage et al. [2010a] to determine anisotropy parameters. We then used a spatial averaging technique combined with a new method of simplified two-dimensional tomography to analyze spatial variations in anisotropy and relate these to stress and structure in the region. Detailed explanations of the methods are provided in the manual discussed in Appendix A. Comparison of shear wave splitting results to stress estimates and local structures let us distinguish the regions in which shear wave splitting is governed by structural anisotropy and those in which stress-induced microcracks are the main cause. Our interpretations agree well with those of Eberhart-Phillips and Reyners [2009] derived from $\mathrm{P}$ wave anisotropy tomography. However, our different observations all sample different levels within the crust. Therefore this 2-D analysis is a first order approximation and more in depth interpretation could be done with the use of a 3-D tomographic inversion of the shear wave splitting parameters.

[45] Coulomb modeling with a dike-like magma reservoir oriented approximately NE-SW was used to calculate the maximum horizontal stress. The pattern of anisotropy, while described well in places by the stress caused by a dike-like magma reservoir and structural effects, could also have a major effect from the loading of the volcanic edifice or other structures such as the Taranaki-Ruapehu line. Finite element modeling, including topography, will illuminate the proportion of the stress causing the shear wave splitting observations that originates from these different sources. The results of this study will be used to measure future changes in anisotropy and to identify the regions of past changes in anisotropy with more confidence.

\section{Appendix A: Obtaining and Using the Programs}

[46] The codes for this method have mainly been written in Matlab and GMT [Wessel and Smith, 1991]. The programs and a detailed technical manual can be found online (https://sites.google.com/site/jessicahelenjohnson/tessa).
[47] Acknowledgments. We gratefully acknowledge funding and support for this research from The Earthquake Commission; The New Zealand Marsden Fund; The Foundation for Research, Science and Technology; and a Victoria University of Wellington PhD Scholarship. We would like to thank Euan Smith, Steven Bannister, Sonja Greve, Andreas Wessel, and Daniel Clarke for providing software and advice on the use of the programs. Focal mechanism inversions were carried out by Carolin Boese. P wave anisotropy measurements were provided by Donna Eberhart-Phillips. Ngauruhoe deployment data, as well as two seismometers for the SADAR experiment, were provided by Art Jolly. We also thank Mark Henderson, Art Jolly, and students at Victoria University of Wellington for field assistance and appreciate the help of VUW students with phase picks. We gratefully acknowledge GeoNet (http://www.geonet.org.nz), a collaborative project funded by the Earthquake Commission (EQC) and operated by GNS Science, for providing earthquake data used in this study. We are particularly grateful to Kevin Fenaughty for help with extracting earthquake arrival time data and seismograms from the GeoNet catalog. We would also like to thank S. Kaneshima and the two anonymous reviewers for their insightful comments, which improved this manuscript.

\section{References}

Adams, C. J., H. J. Campbell, I. J. Graham, and N. Mortimer (1998), Torlesse, waipapa and caples suspect terranes of new zealand: Integrated studies of their geological history in relation to neighbouring terranes, Episodes, 21(4), 235-240.

Arnold, R., and J. Townend (2007), A Bayesian approach to estimating tectonic stress from seismological data, Geophys. J. Int., 170(3), 1336-1356.

Audoine, E., M. K. Savage, and K. Gledhill (2004), Anisotropic structure under a back arc spreading region, the Taupo Volcanic Zone, New Zealand, J. Geophys. Res., 109, B11305, doi:10.1029/2003JB002932.

Babuska, V., and M. Cara (1991), Seismic Anisotropy in the Earth, Mod. Approaches Geophys., vol. 10, Kluwer Acad., Dordrecht, Netherlands.

Beetham, R. D., and W. A. Watters (1985), Geology of Torlesse and Waipapa terrane basement rocks encountered during the Tongariro power development project, North-Island, New-Zealand, N. Z. J. Geol. Geophys. 28(4), 575-594.

Boness, N. L., and M. D. Zoback (2006), Mapping stress and structurally controlled crustal shear velocity anisotropy in California, Geology, 34(10), 825-828.

Bryan, C. J., and S. Sherburn (1999), Seismicity associated with the 19951996 eruptions of Ruapehu volcano, New Zealand: Narrative and insights into physical processes, J. Volcanol. Geotherm. Res., 90(1-2), 1-18.

Crampin, S. (1991), Wave propagation through fluid-filled inclusions of various shapes: Interpretation of extensive-dilatancy anisotropy, Geophys. J. Int., 107, 611-623.

Crampin, S. (1994), The fracture criticality of crustal rocks, Geophys. J. Int., $118(2), 428-438$.

Crotwell, H. P., T. J. Owens, and J. Ritsema (1999), The taup toolkit: Flexible seismic travel-time and ray-path utilities, Seismol. Res. Lett., $70,154-160$

Eberhart-Phillips, D., and M. Reyners (2009), Three-dimensional distribution of seismic anisotropy in the Hikurangi subduction zone beneath the central North Island, New Zealand, J. Geophys. Res., 114, B06301, doi:10.1029/2008JB005947.

Gerst, A., and M. K. Savage (2004), Seismic anisotropy beneath Ruapehu Volcano: A possible eruption forecasting tool, Science, 306(5701), 1543-1547.

Gill, P., W. Murray, and M. Wright (1981), Practical Optimization, Academic, London.

Greve, S. M., M. K. Savage, and S. D. Hofmann (2008), Strong variations in seismic anisotropy across the Hikurangi subduction zone, North Island, New Zealand, Tectonophysics, 462(1-4), 7-21.

Hatchell, P., and S. Bourne (2005), Rocks under strain: Strain-induced time-lapse time shifts are observed for depleting reservoirs, Leading Edge, 24(12), 1222-1225.

Hayes, G., M. Reyners, and G. Stuart (2004), The Waiouru, New Zealand, earthquake swarm: Persistent mid crustal activity near an active volcano, Geophys. Res. Lett., 31, L19613, doi:10.1029/2004GL020709.

Horspool, N. A. (2003), Bending stress and faulting linked to the laod of Ruapehu Volcano, M.S. thesis, Victoria Univ. of Wellington, Wellington, New Zealand.

Houghton, B. F., J. H. Latter, and W. R. Hackett (1987), Volcanic Hazard assessment for Ruapehu composite volcano, Taupo Volcanic Zone, New Zealand, Bull. Volcanol., 49, 737-751.

Hurst, A. W., B. J. Scott, C. Werner, N. Stevens, and H. Cowan (2004), Monitoring New Zealand volcanoes, Tephra, 21, 12-17.

Ingham, M. R., H. M. Bibby, W. Heise, K. A. Jones, P. Cairns, S. Dravitzki, S. L. Bennie, T. G. Caldwell, and Y. Ogawa (2009), A magnetotelluric 
study of Mount Ruapehu volcano, New Zealand, Geophys. J. Int., 179(2), $887-904$.

Johnson, J. H., S. Prejean, M. K. Savage, and J. Townend (2010), Anisotropy, repeating earthquakes, and seismicity associated with the 2008 eruption of Okmok volcano, Alaska, J. Geophys. Res., 115, B00B04, doi:10.1029/2009JB006991.

Johnston, D. M., B. F. Houghton, V. E. Neall, K. R. Ronan, and D. Paton (2000), Impacts of the 1945 and 1995-1996 Ruapehu eruptions, New Zealand: An example of increasing societal vulnerability, Geol. Soc. Am. Bull., 112(5), 720-726.

Kaneshima, S. (1990), Origin of crustal anisotropy: Shear wave splitting studies in Japan, J. Geophys. Res., 95(B7), 11,121-11,133.

Keats, B. S., J. H. Johnson, and M. K. Savage (2011), The Erua earthquake cluster and seismic anisotropy in the Ruapehu region, New Zealand, Geophys. Res. Lett., 38, L16315, doi:10.1029/2011GL049014.

Latter, J. H. (1981), Volcanic earthquakes, and their relationship to eruptions at Ruapehu and Ngauruhoe volcanos, J. Volcanol. Geotherm. Res., 9(4), 293-309.

Lees, J. M., and H. T. Wu (1999), $P$ wave anisotropy, stress, and crack distribution at Coso geothermal field, California, J. Geophys. Res., 104(B8), $17,955-17,973$.

Lin, J., and R. S. Stein (2004), Stress triggering in thrust and subduction earthquakes and stress interaction between the southern San Andreas and nearby thrust and strike-slip faults, J. Geophys. Res., 109, B02303, doi:10.1029/2003JB002607.

Liu, Y. F., T. L. Teng, and Y. Ben-Zion (2004), Systematic analysis of shear-wave splitting in the aftershock zone of the 1999 Chi-Chi, Taiwan, earthquake: Shallow crustal anisotropy and lack of precursory variations, Bull. Seismol. Soc. Am., 94(6), 2330-2347.

Lund, B., and J. Townend (2007), Calculating horizontal stress orientations with full or partial knowledge of the tectonic stress tensor, Geophys. J. Int., $170(3), 1328-1335$.

Miller, V., and M. Savage (2001), Changes in seismic anisotropy after volcanic eruptions: Evidence from Mount Ruapehu, Science, 293(5538), 2231-2233.

Mordret, A., A. D. Jolly, Z. Duputel, and N. Fournier (2010), Monitoring of phreatic eruptions using interferometry on retrieved cross-correlation function from ambient seismic noise: Results from Mt. Ruapehu, New Zealand, J. Volcanol. Geotherm. Res., 191(1-2), 46-59.

Mortimer, N. (2004), New Zealand's geological foundations, Gondwana Res., 7(1), 261-272.

Neall, V. E., B. F. Houghton, S. J. Cronin, S. L. Donogue, K. A. Hodgson, D. M. Johnston, J. A. Lecointre, and A. R. Mitchell (1999), Volcanic Hazards at Ruapehu Volcano, Volcanic Hazards Inf. Ser., vol. 8, Minist. of Civ. Def., Wellington, New Zealand.

Nistala, S., and G. A. McMechan (2005), 3D Modeling of fracture-induced shear-wave splitting in the Southern California basin, Bull. Seismol. Soc. Am., 95(3), 1090-1100.

Nuttli, O. (1961), The effect of the Earth's surface on the S wave particle motion, Bull. Seismol. Soc. Am., 51(2), 237-246.

Peng, Z. G., and Y. Ben-Zion (2004), Systematic analysis of crustal anisotropy along the Karadere-Duzce branch of the North Anatolian fault, Geophys. J. Int., 159(1), 253-274.

Price, R. C., J. A. Gamble, I. E. M. Smith, R. B. Stewart, S. Eggins, and I. C. Wnight (2005), An integrated model for the temporal evolution of andesites and rhyolites and crustal development in New Zealand's North Island, J. Volcanol. Geotherm. Res., 140(1-3), 1-24.

Price, R. C., R. George, J. A. Gamble, S. Turner, I. E. M. Smith, C. Cook, B. Hobden, and A. Dosseto (2007), U-Th-Ra fractionation during crustallevel andesite formation at Ruapehu volcano, New Zealand, Chem. Geol., $244,437-451$.

Reasenberg, P., and D. Oppenheimer (1985), FPFIT, FPPLOT and FPPAGE: Fortran computer programs for calculating and displaying earthquake fault-plane solutions, U.S. Geol. Surv. Open File Rep., 109, 85-739.

Reyners, M. (2010), Stress and strain from earthquakes at the southern termination of the Taupo Volcanic Zone, New Zealand, J. Volcanol. Geotherm. Res., 190(1-2), 82-88.

Risk, G. F., H. M. Bibby, C. J. Bromley, T. G. Caldwell, and S. L. Bennie (2002), Appraisal of the Tokaanu-Waihi geothermal field and its relationship with the Tongariro geothermal field, New Zealand, Geothermics, 31(1), 45-68.

Rowland, J. V., and R. H. Sibson (2001), Extensional fault kinematics within the Taupo volcanic zone, New Zealand: Soft-linked segmentation of a continental rift system, N. Z. J. Geol. Geophys., 44(2), 271-283.

Rumpker, G., and P. G. Silver (2000), Calculating splitting parameters for plume-type anisotropic structures of the upper mantle, Geophys. J. Int., 143(3), 507-520.
Savage, M. K., A. Wessel, N. A. Teanby, and A. W. Hurst (2010a), Automatic measurement of shear wave splitting and applications to time varying anisotropy at Mount Ruapehu volcano, New Zealand, J. Geophys. Res., 115, B12321, doi:10.1029/2010JB007722.

Savage, M. K., T. Ohminato, Y. Aoki, H. Tsuji, and S. M. Greve (2010b), Stress magnitude and its temporal variation at Mt. Asama Volcano, Japan, from seismic anisotropy and GPS, Earth Planet. Sci. Lett., 290(3-4), 403-414.

Sayers, C. M., and M. Kachanov (1995), Microcrack-induced elastic-wave anisotropy of brittle rocks, J. Geophys. Res., 100(B3), 4149-4156.

Seward, A. M., C. M. Henderson, and E. G. C. Smith (2009), Models of the upper mantle beneath the central North Island, New Zealand, from speeds and anisotropy of subhorizontal $\mathrm{P}$ waves (Pn), J. Geophys. Res., 114, B01301, doi:10.1029/2008JB005805.

Sherburn, S., and R. S. White (2005), Crustal seismicity in Taranaki, New Zealand using accurate hypocentres from a dense network, Geophys. J. Int., 162(2), 494-506.

Sherburn, S., and R. S. White (2006), Tectonics of the Taranaki region, New Zealand: earthquake focal mechanisms and stress axes, N. Z. J Geol. Geophys., 49(2), 269-279.

Sherburn, S., J. Townend, R. Arnold, and L. Woods (2009), EQC Project 08/550 - Establishing a spatiotemporal benchmark for ongoing crustal stress monitoring in the southern Taupo volcanic zone, GNS Sci. Consultancy Rep. 185, 44 pp.

Silver, P. G., and W. W. Chan (1991), Shear-wave splitting and subcontinental mantle deformation, J. Geophys. Res., 96(B10), 16,429-16,454.

Stern, T. A., W. R. Stratford, and M. L. Salmon (2006), Subduction evolution and mantle dynamics at a continental margin: Central North Island, New Zealand, Rev. Geophys., 44, RG4002, doi:10.1029/2005RG000171.

Teanby, N. A., J.-M. Kendall, and M. van der Baan (2004), Automation of shear-wave splitting measurements using Cluster analysis, Bull. Seismol. Soc. Am., 94(2), 453-463, doi:10.1785/0120030123.

Titzschkau, T., M. Savage, and T. Hurst (2010), Changes in attenuation related to eruptions of Mt. Ruapehu Volcano, New Zealand, J. Volcanol. Geotherm. Res., 190(1-2), 168-178.

Toda, S., R. S. Stein, K. Richards-Dinger, and S. B. Bozkurt (2005), Forecasting the evolution of seismicity in southern California: Animations built on earthquake stress transfer, J. Geophys. Res., 110, B05S16, doi:10.1029/2004JB003415.

Townend, J., and M. D. Zoback (2001), Implications of earthquake focal mechanisms for the frictional strength of the San Andreas fault system, Geol. Soc. Spec. Publ., 186(1), 13-21, doi:10.1144/GSL.SP.2001. 186.01.02.

Townend, J., and M. D. Zoback (2004), Regional tectonic stress near the San Andreas fault in central and southern California, Geophys. Res. Lett., 31, L15S11, doi:10.1029/2003GL018918.

Turnbull, I. M., N. Mortimer, and D. Craw (2001), Textural zones in the Haast Schist: A reappraisal, N. Z. J. Geol. Geophys., 44(1), 171-183.

Villamor, P., and K. R. Berryman (2006), Evolution of the southern termination of the Taupo Rift, New Zealand, N. Z. J. Geol. Geophys., 49(1), 23-37.

Wallace, L. M., J. Beavan, R. McCaffrey, and D. Darby (2004), Subduction zone coupling and tectonic block rotations in the North Island, New Zealand, J. Geophys. Res., 109, B12406, doi:10.1029/2004JB003241.

Wessel, P., and W. H. F. Smith (1991), Free software helps map and display data, Eos Trans. $A G U, 72(41), 445$.

Wilson, C. J. N., B. F. Houghton, M. O. McWilliams, M. A. Lanphere, S. D. Weaver, and R. M. Briggs (1995), Volcanic and structural evolution of Taupo Volcanic Zone, New-Zealand: A review, J. Volcanol. Geotherm. Res., 68(1-3), 1-28.

Wood, R., and B. Davy (1994), The Hikurangi Plateau, Mar. Geol., 118(1-2), 153-173.

Yardley, G. S., and S. Crampin (1991), Extensive-dilatancy anisotropy: Relative information in vsps and reflection surveys, Geophys. Prospect., 39, 337-355, doi:10.1111/j.1365-2478.1991.tb00316.

Zhang, H. J., Y. F. Liu, C. Thurber, and S. Roecker (2007), Three-dimensional shear-wave splitting tomography in the Parkfield, California, region, Geophys. Res. Lett., 34, L24308, doi:10.1029/2007GL031951.

Zinke, J. C., and M. D. Zoback (2000), Structure-related and stress-induced shear-wave velocity anisotropy: Observations from microearthquakes near the Calaveras fault in central California, B Bull. Seismol. Soc. Am. 90(5), 1305-1312.

J. H. Johnson, Hawaiian Volcano Observatory, USGS, P.O. Box 51, Hawaii National Park, HI 96718-0051, USA. (jessjohnson@usgs.gov)

M. K. Savage and J. Townend, School of Geography, Environment and Earth Sciences, Victoria University of Wellington, PO Box 600, Wellington 6140, New Zealand. 